\title{
LA TUTELA DEL COMPRADOR FRENTE A LA AUSENCIA DE CALIDADES PRESUPUESTAS EN LA COSA
}

[Buyer Protection in the Lack of Quality the Item Purchased Should Have Had]

\author{
Iñigo DE la MAZa Gazmuri* \\ Universidad Diego Portales, Santiago, Chile
}

\begin{abstract}
RESUMEN
Este trabajo intenta mostrar que el actual sistema de protección del comprador frente a cumplimientos imperfectos causados por la ausencia de cualidades presupuestas en la cosa es extremada e innecesariamente complejo. Se sugiere la posibilidad de aligerar esa complejidad recurriendo a ciertos modelos bien asentados en el derecho comparado.
\end{abstract}

Palabras Clave

Incumplimiento contractual - Tutela del comprador - Nuevo derecho de las obligaciones.

\begin{abstract}
The purpose of this work is to show that the current consumer protection system, in cases of partial fulfillments caused by the lack of the qualities that the item purchases should have had, is extremely and unnecessary complex. The possibility of reducing said complexity by resorting to well established models in the comparative law is suggested.
\end{abstract}

\section{KEYWORDS}

Breach of contract - Buyer protection - New law of obligations.

RECiBIDo el 8 de agosto y ACEPTADo el 22 de diciembre de 2014

* Doctor en Derecho por la Universidad Autónoma de Madrid, profesor investigador en la Facultad de Derecho de la Universidad Diego Portales. Dirección postal: República 105, Santiago de Chile. Correo electrónico: inigo.delamaza@udp.cl. Este artículo se enmarca en el Proyecto FonDECYT regular No 1120548: "El tratamiento de las entregas defectuosas en el derecho chileno: hacia una noción de incumplimiento amplia y unitaria”. 


\section{INTRODUCCIÓN}

¿Cómo se protege al comprador frente a la ausencia de calidades presupuestas de la cosa? Esa es la pregunta en torno a la cual se endereza este trabajo. Para considerarla convendrá formular un par de precisiones preliminares respecto a la expresión "calidades presupuestas". La primera de ellas es que tal como la empleo aquí no cubre ni vicios jurídicos ni derechos de terceros sobre la $\cos \mathrm{a}^{1}$. La segunda precisión se refiere a la expresión "presupuesta" y es que la empleo para referirme a calidades que, de alguna manera, se han incorporado al contrato ${ }^{2}$, por lo mismo, la entrega de la cosa sin esas cualidades configura lo que suele denominarse un "cumplimiento imperfecto" 3 .

Pues bien, formuladas las precisiones, volvamos a la pregunta. Para enfrentarla me he servido de dos importantes sentencias de la Corte Suprema en las que se muestra de manera bien elocuente que, frente a un cumplimiento imperfecto por ausencia de las cualidades presupuestas de la cosa, existen una serie de mecanismos a través de los cuales resulta posible incardinar la pretensión del comprador insatisfecho. De esta manera es posible identificar el error vicio del consentimiento, la inexistencia parcial del objeto, la disciplina de los vicios redhibitorios y las acciones generales derivadas del incumplimiento de la obligación de entrega. A esto se refiere la primera parte de este trabajo.

El objetivo de la segunda parte consiste en mostrar la posibilidad de concursos entre estos distintos mecanismos a través de los cuales el comprador puede tutelar sus intereses. Entiendo por concurso aquella situación que tiene lugar cuando el mismo conjunto de circunstancias configura el supuesto de hecho de diversos medios de tutela de los cuales puede servirse el acreedor. En esta segunda parte introduzco, además, la distinción entre concursos horizontales (entre medios de tutela generales y especiales) y verticales (entre medios de tutela frente al incumplimiento [generales o especiales] y acciones relacionadas con la validez del contrato. Considero los siguientes concursos: resolución y vicios redhibitorios, normas generales y especiales de daños, error y acción resolutoria, el error y los vicios redhibitorios y las acciones del artículo 1814 en relación a las anteriores. La conclusión de esta segunda parte es que la posibilidad de concurso es realmente abundante.

La tercera parte de este trabajo tiene por objetivo considerar cómo han de resolverse algunos de esos concursos, aquellos que se presentan con ma-

${ }^{1}$ El tratamiento de estas cuestiones es el objeto de un nuevo proyecto FONDECYT.

${ }^{2}$ Respecto a la incorporación al contrato puede consultarse Morales Moreno, Antonio Manuel, El error en los contratos (Madrid, Ceura, 1988), pp. 197-210.

${ }^{3}$ Sobre el tema puede consultarse De LA MAZa Gazmuri, Iñigo, El régimen de los cumplimientos defectuosos en la compraventa, en Revista Chilena de Derecho, 39 (2012) 3. 
yor asiduidad frente a los tribunales y a los que la doctrina ha puesto mayor atención. Una vez más me sirvo de la distinción entre concursos horizontales y verticales y considero la situación del concurso entre acción resolutoria y acción redhibitoria, entre la acción de daños del artículo 1861 y aquella de carácter general, la acción resolutoria y la correspondiente al error, y entre la acción rescisoria y la de error. La conclusión de esta tercera parte es que la solución a los concursos no necesaria ni frecuentemente es unívoca y que las discusiones obedecen, en general, a que los perfiles de los medios de tutela no se encuentran suficientemente precisados en el ordenamiento jurídico. En definitiva, la conclusión es que se trata de un sistema de tutela del acreedor extremada e innecesariamente complejo.

La cuarta y última parte se encuentra destinada a mostrar algunas líneas generales acerca de cómo puede simplificarse este sistema de tutela. Considero, en primer lugar, la noción de incumplimiento que deberíamos adoptar; en segundo lugar, me ocupo -aunque muy brevemente- de la articulación de los medios de tutela. Lo anterior, creo, permite hacerse cargo satisfactoriamente de los concursos horizontales. En tercer lugar, propongo un par de soluciones para los concursos verticales y opto por una de ellas.

\section{A PROPÓSITO DE DOS SENTENCIAS DE LA CORTE SUPREMA}

\section{Los hechos.}

En este apartado me interesa presentar los hechos que originaron dos sentencias de la Corte Suprema cuya importancia, me parece, seguimos descubriendo. La primera de ellas es del 27 de julio de $2005^{4}$; la segunda es de 31 de octubre de $2012^{5}$.

Con respecto a la sentencia del 27 de julio de 2005, los hechos -aquellos que quedaron acreditados en el juicio y que resultan relevantes a los efectos de este trabajo- se presentan a propósito de un contrato de compraventa. Según consta en el considerando noveno de la sentencia de primera instancia se estableció que el objeto de la obligación del vendedor consistía en 7.000 kilos de "sal nitrificada" en una concentración del 0,8\%. La vendedora entregó la cantidad de sal acordada, sin embargo, la concentración era del 8.0\%, es decir "sal de cura".

Resulta de interés aquí advertir que la compradora de la sal era una sociedad dedicada a la fabricación de cecinas y que la sal iba destinada a esta actividad. Por otra parte, señala la compradora en su demanda, de acuerdo al artículo 310 del Reglamento sanitario de los alimentos la sal empleada en

\footnotetext{
${ }^{4}$ “Cecinas La Preferida S.A. con Sociedad Comercial Salinak Limitada” (2005).

5 "Zorin S.A. con Compañía Siderúrgica Huachipato S. A." (2012).
} 
la fabricación de cecinas no puede exceder, en su concentración de $0,8 \%$. En fin, se señala en la demanda que debido al uso de la sal en la elaboración de las cecinas, se perdieron 23.214 kilos de este producto.

Por su parte, la demandada no controvirtió que hubiera entregado sal de cura; cuestionó, en cambio, que las partes hubieran convenido como objeto del contrato sal nitrificada y, según se lee en la sentencia de primera instancia, estimó que, si así fuera, lo que habría existido era:

un vicio del consentimiento consistente en un error de hecho en cuanto a la identidad de la cosa específica de que se trata, lo que no ha sido alegado por su contendora mediante el ejercicio de la acción de nulidad correspondiente.

Por lo que toca a la sentencia de 31 de octubre de 2012, una vez más, se trata de una compraventa. El objeto cuya entrega debía la vendedora, esta vez, según consta del considerando sexto de la sentencia de reemplazo de la Corte Suprema, eran 1.500 toneladas de rodillos de laminación en desuso, que debían tener una determinada composición química, particularmente de níquel.

Los rodillos le fueron ofrecidos a la demandante por un representante de la demandada. La demandante los compró determinada por la alta concentración de Níquel que poseían. Con posterioridad, la demandante los vendió a una empresa estadounidense y, para proceder a su entrega, incurrió en un complejo y costoso proceso de laminación. Luego de concluido el proceso, la demandante envió una primera partida de 58 toneladas del metal a la empresa estadounidense, la que le informó que los rodillos carecían de la concentración de níquel que se le había asegurado.

Como en el caso anterior, la demandada no controvirtió la falta de concentración de níquel en los rodillos entregados; lo que, en cambio, negó es que la concentración de níquel alegada por la demandante fuera parte de su obligación.

\section{La incardinación de las pretensiones de las partes.}

La breve descripción de los hechos resulta, desde luego, insuficiente para calibrar en su totalidad la complejidad de los casos. Sin embargo, presta una utilidad más modesta, pero suficiente a los efectos de estas páginas. Nos permite considerar la incardinación de las pretensiones de las partes en los mecanismos de tutela $-o$, si se quiere, remedios- que el ordenamiento jurídico les franquea.

$\mathrm{Al}$ considerar esta incardinación no me limitaré únicamente a la forma en que las demandantes calificaron jurídicamente los hechos, sino que, añadiré alguna calificación realizada por una de las demandadas y por los tribunales.

Prestando atención a todo esto - y con la vista puesta en las dos sentencias- me parece que las posibilidades de incardinación son las siguientes: 
error vicio del consentimiento, inexistencia parcial, vicio redhibitorio e incumplimiento de la obligación de entrega.

Antes de considerarlas por separado me parece útil prevenir que no estoy afirmando ninguna de las siguientes dos declaraciones: $i$ ) que esa incardinación sea necesariamente correcta; y ii) que esas sean las únicas formas posibles de incardinación. En vez de esto estoy mostrando la forma en que incardinaron las demandantes sus pretensiones; la forma en que las demandadas consideraron que debían hacerlo y, en fin, la forma en que los tribunales lo decidieron.

Ahora convendrá presentar de manera separada las distintas formas de incardinación.

\section{El error vicio del consentimiento.}

Hemos de considerar sólo la sentencia de 27 de julio de 2005. La razón es que únicamente en ella las partes o los jueces se refirieron al error. Específicamente, como ya ha quedado dicho, fue la demandada quien señaló que no había existido incumplimiento de su parte, sino que había existido un error de hecho en cuanto a la identidad de la cosa específica.

Y lo que tendremos que entender es que la demandada consideró que nos encontrábamos en presencia de un error obstáculo, en la medida en que ambas partes habían depositado su voluntad sobre objetos distintos. La demandada había entendido obligarse a entregar sal de cura; la demandante estimaba que su acreencia correspondía a sal nitrificada.

En su sentencia de reemplazo la Corte Suprema se refirió al error en el considerando segundo en los siguientes términos: "Que el artículo $1828 \mathrm{del}$ Código Civil expresa que 'el vendedor es obligado a entregar lo que reza el contrato', de lo que se sigue que, aunque en el caso de autos el vendedor cumplió con su obligación de entregar la cosa la sal lo hizo en forma imperfecta al entregar sal en una concentración distinta a la requerida por el comprador. Esta materia se encuentra tratada en el artículo 1454 del Código Civil, referida al error de becho que se produce cuando 'la sustancia o calidad esencial del objeto sobre el que versa el acto o contrato, es diversa de lo que se cree".

En el considerando siguiente, la Corte señala que, sin embargo, en este caso, no se demandó la nulidad del contrato, sino la resolución; por lo mismo, la sentencia debía enderezarse en esa dirección. De esta manera -aunque obiter dictum - la Corte parece compartir la posición del demandado: en los hechos habría existido un error. Con todo, la Corte cambia la calificación del error. La demandada había entendido que era un error obstáculo. La Corte en cambio radica el error en el artículo 1454, estimándolo como substancial ${ }^{6}$.

${ }^{6}$ El cambio de calificación parece erróneo. La Corte estima que existió aquí un 


\section{Inexistencia parcial del objeto.}

Respecto de la inexistencia parcial del objeto nos ocupa exclusivamente la sentencia de 31 de octubre de 2012. En este caso no fueron las partes quienes calificaron los hechos como inexistencia parcial del objeto, sino, únicamente, el tribunal de primera instancia.

Conociendo de la demanda de indemnización de perjuicios por incumplimiento de la vendedora, el Tribunal de primera instancia consideró, en el considerando $8^{\circ}$ de su sentencia lo siguiente: "Que la venta de una cosa que al tiempo de perfeccionarse el contrato se supone existente y no existe, no produce efecto alguno. Sin embargo, el que vendió a sabiendas lo que en el todo o en una parte considerable no existía, resarcirá los perjuicios al comprador de buena fe".

En otras palabras, la jueza del Quinto Juzgado Civil de Santiago estimó que los hechos que le presentaban las partes resultaban susceptibles de incardinarse en la disciplina del artículo 1814. Por su parte, la Séptima Sala de la Corte de Apelaciones de Santiago no concedió ni la casación en la forma ni la apelación con que la demandada buscó controvertir la sentencia de primera instancia. De manera que, podremos convenirlo, aceptó lo mismo que la jueza de primera instancia.

Distintas fueron las cosas ante la Corte Suprema, que acogió el recurso de casación en la forma en los siguientes términos: "Que entrando en el recurso de casación en la forma, efectivamente tiene razón el recurrente cuando advierte que la sentencia recurrida, al hacer suyos los considerandos de primera

error sobre las cualidades esenciales. Sin embargo, a la vez, declaró resuelto el contrato justificando su decisión en un supuesto de aliud pro alio (Sobre el aliud pro alio [es decir, la entrega de una cosa distinta a la pactada] puede consultarse Oviedo Albán, Jorge, La garantía por vicios ocultos en la compraventa (tesis doctoral, Santiago, Universidad de los Andes, 2012), pp. 224-238. Ambas cuestiones, por supuesto, resultan incompatibles. Existe aliud pro alio cuando se entrega una cuestión distinta de la debida. En cambio, un error sobre las cualidades esenciales tiene lugar cuando se entrega la cosa debida, pero "la sustancia o calidad esencial del objeto sobre el que versa el acto o contrato es diversa de lo que se cree." Un supuesto de aliud pro alio puede coincidir con uno de error, pero con uno de error obstáculo, es decir cuando recae sobre "sobre la identidad especifica de que se trata”. Así, por ejemplo, puede desprenderse de una sentencia de la Corte Suprema de 30 de mayo de 2001 ("José Ortelio García Pinilla, Nelson Albornoz Ruedlinger” [2001]). En los hechos, se avisó la subasta pública de una especie o cuerpo cierto cuando, en realidad, lo que se estaba subastando eran derechos sobre la propiedad. De esta manera, en el considerando quinto de la sentencia de la Corte Suprema se lee: Que en la especie, de acuerdo con los presupuestos fácticos resumidos en el considerando segundo, los demandantes, fundadamente creyeron adquirir el dominio pleno sobre el inmueble ubicado en Portales No 361 de Temuco, en circunstancias que se trataba de la venta de una cuota equivalente al $50 \%$ de dicho derecho de dominio, desde que en las bases de remate se indicó que se vendía el inmueble e igual cosa sucedió en las publicaciones de los avisos respectivos. 
instancia, fundamentó su fallo en un disposición que no habia sido invocada por la parte demandante, cual es el artículo 1814 del Código Civil, norma a partir de la cual la sentencia justifica la condena indemnizatoria en favor del demandante. A este respecto debe tenerse presente que el demandante no ha pedido la inexistencia o nulidad del contrato cuyo incumplimiento denuncia, sino la indemnización de perjuicios derivada del incumplimiento del vendedor. Por ello resulta incongruente que la sentencia recurrida fundamente la condena indemnizatoria en una disposición, como es el artículo 1814, cuya hipótesis de hecho no encaja con lo motivado en la sentencia. En efecto, en su inciso primero, supone que el contrato es nulo o inexistente: 'La venta de una cosa que al tiempo de perfeccionarse el contrato se supone existente y no existe, no produce efecto alguno'. El inciso segundo de la regla citada confiere al comprador una acción alternativa, bajo el supuesto que falte una parte considerable de ella al tiempo de perfeccionarse el contrato: 'desistir del contrato, o darlo por subsistente, abonando el precio a justa tasación'. El inciso tercero legitima al comprador de buena fe para demandar de perjuicios al vendedor que 'a sabiendas vendió lo que en el todo o en una parte considerable no existia'. De lo expuesto es claro que ninguna de las hipótesis de hecho que se describen en esta norma, y que ha servido para fundar el fallo, encaja con los fundamentos con que el demandante apoya su demanda, que, como se ha dicho, asumen que se trata de un contrato válido, sin pedirse la nulidad o la resolución de mismo".

Entonces, deberemos entender que el problema se encuentra en la discordancia que existe entre las hipótesis que contiene el artículo 1814 y los fundamentos con que el demandante apoyó su demanda. Lo que, sin embargo, no resulta del todo claro de la opinión de la Corte Suprema es si alguna de las hipótesis del 1814 se presentaba en este caso o no. Más adelante volveré sobre esta cuestión.

\section{Vicios redhibitorios.}

A diferencia del error y de la inexistencia parcial del objeto, los vicios redhibitorios se presentan en ambos casos. De manera que convendrá considerarlos por separado.

a) Podemos comenzar por la sentencia de 27 de julio de 2005. La actora presentó una demanda en la que, en lo principal, solicitaba la resolución del contrato y, en subsidio, la rescisión por vicios redhibitorios.

Aquí, únicamente, ha de preocuparnos, la pretensión subsidiaria. En esta tarea nos prestarán utilidad los considerandos $5^{\circ}$ a $7^{\circ}$ de la sentencia de la Corte Suprema. El tenor del primero es el siguiente: " $5^{\circ}$ A primera vista, pareciera que se trataría de un caso de vicio redhibitorio, definido en el articulo 1.857 del Código Civil, como la acción que tiene el compradorparapedir que se 'rescinda' la venta o se rebaje proporcionalmente el precio, por los vicios ocultos 
de la cosa vendida./Sin embargo, ha de destacarse que la acción antedicha, cuyos requisitos de procedencia se encuentran en el articulo 1.858 del Código Civil, constituye una excepción a la regla general de que el incumplimiento de las obligaciones de un contrato bilateral da origen a la acción resolutoria, debiendo entenderse que aun cuando el legislador califica constantemente la acción por vicios redhibitorios como una acción rescisoria, lo cierto es que, en verdad, es una acción resolutoria especialy con reglamentación diferente a la regla general del articulo 1.489 del texto legal señalado". El considerando 6 expresa: "Que, en consecuencia, la situación se traduce en que, ante el cumplimiento imperfecto de la obligación de entregar, puede suceder que se reúnan los requisitos de los vicios ocultos, en cuyo caso se aplican las normas del párrafo $8^{\circ}$ del Titulo XXIII del Libro Cuarto del Código Civil, pero si no se dan dichas exigencias puede reclamarse el cumplimiento de la obligación de entregar por parte del vendedor, a través del artículo 1.489 del Código Civil, si concurren los presupuestos que exige la norma, dando lugar asi a la aplicación de la condición resolutoria tácita de este precepto de aplicación general". Por su parte, el considerando $7^{\circ}$ declara: "Que, de acuerdo a las disposiciones que reglamentan la institución de los vicios ocultos, ellas se aplican cuando entregada la cosa realmente vendida, ésta resulta tener un vicio existente al tiempo de la venta, pero que no puede ser advertido por el comprador, lo que en este caso se cumple, como se encuentra establecido en autos. Pero ello sólo puede tener lugar cuando la cosa entregada es realmente la vendida, lo que no acontece en autos, donde la cosa entregada es otra, como ha quedado establecido en la sentencia de primer grado".

Frente a la demanda subsidiaria, entonces, los tribunales que conocieron de ella estimaron que, en la especie no existían vicios redhibitorios pues para que así fuera tendría que ser el caso que se entregara la cosa debida y que esta presentara defectos susceptibles de encuadrarse en lo dispuesto por el artículo 1858. Lo que, en opinión de los tribunales, había sucedido en este caso es que se había entregado una cosa distinta a la debida.

b) Podemos ocuparnos ahora de la sentencia de 31 de octubre de 2012. En este caso la alusión a los vicios redhibitorios corrió de parte de la demandada, como una forma de defenderse frente a la pretensión indemnizatoria de la demandante.

Estimó la demandada que la acción de daños era la propia de los vicios redhibitorios, por lo mismo, se encontraba prescrita. La Corte Suprema se hizo cargo de esta defensa en el considerando $21^{\circ}$ en los siguientes términos: "Que en relación con la excepción de prescripción opuesta por la demandada a fs. 755 bis, tampoco será acogida, pues en ella se asume que la acción deducida en autos es la derivada de una indemnización por los vicios redhibitorios del contrato de compraventa, conforme con los artículos 1861,1866 y 1867 del Código Civil, que no es el caso. Como se ha desarrollado en los considerandos primero a cuarto 
de esta sentencia de reemplazo, la acción indemnizatoria deducida en autos es la general de la responsabilidad contractual, cuya prescripción es de cinco años. En autos hay constancia que el plazo de prescripción de la acción intentada no se cumplió, desde el momento que se demandó por el incumplimiento de un contrato celebrado el 10 de mayo de 2007 y el demandado aparece dándose por notificado con fecha $1^{\circ}$ de octubre de 2008, por lo que no existe fundamento para alegar la prescripción extintiva de la acción intentada en autos".

Como se ve, la Corte Suprema despeja la defensa de la demandada porque entiende que se trata de una defensa a una acción que no se intentó. La demandante no había alegado la presencia de vicios redhibitorios para justificar su pretensión indemnizatoria, sino lo que la Corte denomina la acción indemnizatoria "general de responsabilidad contractual".

\section{Incumplimiento de la obligación de entrega.}

Bajo la expresión "incumplimiento de la obligación de entrega" voy a cubrir dos formas diversas de incardinar la pretensión de las demandantes. La primera de ellas es la acción resolutoria, la segunda es la acción indemnizatoria. La primera corresponde a la sentencia de 27 de julio de 2005 y la segunda a la sentencia de 31 de octubre de 2012. En ese orden las presento.

a) Tratándose de la sentencia de 27 de julio de 2005 , como ya ha quedado dicho, la demandante canalizó su pretensión demandando, en lo principal, la resolución del contrato. Al considerar la opinión de la Corte Suprema transcrita a propósito de los vicios redhibitorios encontramos que el Tribunal consideró, en el considerando $7^{\circ}$ de su sentencia: "que el incumplimiento del vendedor reúne todos los requisitos para que proceda la resolución del contrato".

b) Por su parte, en lo que concierne a la sentencia de 31 de octubre de 2012, luego de dar por establecido el incumplimiento contractual, el tribunal comienza -a partir del considerando $9^{\circ}$ de su sentencia- a establecer la procedencia de la acción indemnizatoria de los artículos 1489 y 1826 . En primer lugar, desestima la alegación de la compradora según la cual, toda vez que la compradora, en conformidad al artículo 160 CCom., no reclamó dentro de los ocho días siguientes de recibida la factura, habría precluido su derecho de hacerlo. A continuación, niega lugar a la defensa consistente en que el objeto del contrato eran exclusivamente rodillos en desuso y no se había contemplado la concentración de níquel. En tercer lugar, no acoge la excepción de contrato no cumplido. Finalmente, en cuarto lugar desestima la alegación de la demandada según la cual, la acción de daños debía intentarse aparejada a la pretensión de cumplimiento forzado o a la pretensión resolutoria, cosa que en este caso no había sucedido. En definitiva, entonces, la Corte Suprema considera incumplido el contrato y concede, con cargo a lo dispuesto en los artículos 1489 y 1826 una indemnización de perjuicios. 
Como puede advertirse, en ambas sentencias la Corte calificó la conducta del demandado como un incumplimiento de la obligación de entrega que justificaba, en un caso, la resolución del contrato y, en otro, una indemnización de perjuicios.

\section{Sintesis.}

En esta primera parte del trabajo he querido mostrar cómo las partes o los tribunales habían considerado la incardinación de las pretensiones y el resumen es que, en ambos casos las demandantes consideraron que había existido un incumplimiento contractual de la obligación de entrega que activaba el régimen general de tutela del comprador ${ }^{7}$; en ambos casos los tribunales estuvieron de acuerdo. Una de las demandantes y una de las demandadas estimó que también podría haber tenido lugar el supuesto de los vicios redhibitorios. En ambos casos, aunque por razones distintas, los tribunales no acogieron esa pretensión. En fin, un tribunal de instancia y una corte de apelaciones consideraron que en el caso de los rodillos de laminación en desuso se habían satisfecho las circunstancias que configuraban el supuesto de hecho de una de las hipótesis contempladas en el artículo 1814. Finalmente, en el caso de la sal nitrificada, tanto la demandada como la Corte Suprema consideraron que había existido un error, aunque, aparentemente, no estuvieron de acuerdo en qué tipo de error era ése.

\section{LOS CONCURSOS DE TUTELAS}

Este es un trabajo acerca de la tutela del acreedor frente a entregas defectuosas. Específicamente, aquellas que obedecen a la ausencia de cualidades presupuestas en la cosa tratándose del contrato de compraventa. Como ha de resultar evidente, las sentencias de las que me he servido no agotan el tema, pero, por así decirlo, proveen de un marco para considerarlo.

La primera cuestión que parecen enseñarnos las sentencias es que las circunstancias que configuran la ausencia de cualidades presupuestas en la cosa, eventualmente, pueden corresponder al supuesto de hecho de diversos medios de tutela del acreedor. A esta situación, siguiendo una nomenclatura de la cual me he servido en otros lugares, voy a denominarla "concurso".

La segunda cuestión a la que quiero prestar atención ( $\mathrm{y}$ a la que dedicaré la tercera parte de este trabajo) es cómo hemos de enfrentar esos concursos.

${ }^{7} \mathrm{Me}$ he referido a este régimen de tutela en DE LA MAZA Gazmuri, I., El régimen de los cumplimientos defectuosos, cit. (n. 3).

${ }^{8}$ Ibíd.; y De la Maza Gazmuri, Iñigo (editor), Incumplimiento contractual: nuevas perspectivas (Cuadernos de Análisis Jurídicos, Colección de Derecho Privado VII, Santiago, U. Diego Portales, 2011). 
$\mathrm{El}$ antecedente que podemos desprender de estas sentencias al respecto es más bien leve. Se trata de la sentencia de 27 de julio de 2005; de ella aprendemos que es posible $i$ ) que concurran, a la vez, los requisitos del error con trascendencia anulatoria y de la acción resolutoria; y ii) que sucediendo lo anterior, el acreedor puede elegir a través de cuál de estos dos dispositivos canalizar sus pretensiones.

Estas dos cuestiones, según creo, son las que configuran el marco desde el cual nos aproximemos a la tutela del acreedor. Por lo tanto, habrá que considerar, primero, la idea de concurso y luego, en la tercera parte, la forma de resolverlo.

\section{La idea de concurso de tutelas.}

Una peculiaridad suficientemente acentuada de los códigos civiles del siglo XIX -entre ellos, el de Chile es que en ellos conviven lo que podríamos denominar "normas generales de tutela al acreedor" y "normas especiales de tutela al acreedor". Para ilustrar esta convivencia podemos servirnos de la sentencia de 27 de julio de 2005 , específicamente de su considerando $5^{\circ}$ y recordar que allí se señala que el artículo 1858 constituye una excepción a la regla general de que el incumplimiento de los contratos bilaterales da origen a la acción resolutoria, debiendo entenderse que aun cuando el legislador califica constantemente la acción por vicios redhibitorios como una acción rescisoria, lo cierto es que, en verdad, es una acción resolutoria especial y con reglamentación diferente a la regla general del artículo 1489.

$\mathrm{Al}$ abrigo de esta declaración podemos percibir que la regla del artículo 1489 contendría una norma general respecto del incumplimiento de las obligaciones del vendedor; en cambio, el artículo 1858 correspondería a una norma especial ${ }^{10}$.

Según espero mostrar, esta convivencia de normas generales y especiales de tutela del acreedor presenta importantes desafíos a la hora de considerar la operativa de la defensa del comprador frente al incumplimiento de su vendedor.

Sin embargo, el desafío puede ser aún mayor. Porque, como nos muestran las dos sentencias consideradas hasta aquí, no es solo que la tutela de la posición del acreedor exija considerar la existencia de reglas generales y

${ }^{9}$ Morales Moreno, Antonio Manuel, Evolución del concepto de obligación en derecho español, en El Mismo, La modernización del derecho de obligaciones (Cizur Menor [Navarra], Thomson - Civitas, 2006), pp. 22-24.

${ }^{10}$ Por su parte, como ha señalado Alessandri Rodríguez, Arturo, De la compraventa y de la promesa de venta (reimpresión Santiago, Editorial Jurídica de Chile, 2003), p. 779, el artículo 1826 no sería "sino la reproducción de la regla general que para todo contrato sinalagmático consigna el artículo 1489 del Código Civil.” 
especiales sobre el incumplimiento del vendedor, sino, además, que debamos tener en cuenta normas sobre validez del contrato. Así, la sentencia de 27 de julio de 2005 nos enseña a tener presente la normativa del error vicio del consentimiento, y la sentencia de 31 de octubre de 2012 sugiere que también pueden presentarse cuestiones acerca de inexistencia del objeto.

De esta manera, quedamos frente a la siguiente situación: considerar adecuadamente la tutela del acreedor frente al tipo de incumplimientos a que refiere este trabajo exige prestar atención, de una parte, a la convivencia de normas generales y especiales de tutela del acreedor y, de otra, a la convivencia de estas normas de tutela con aquellas que disciplinan la validez del contrato.

La forma de prestar atención a esta convivencia consiste en determinar si es posible que se presente concurso entre normas generales y especiales de tutela del acreedor y entre esas normas y aquellas de validez del contrato. $Y$ la tarea consistirá aquí en precisar si resulta posible que las mismas circunstancias configuren, a la vez, el supuesto de hecho de las normas generales y especiales relativas al incumplimiento contractual y de las normas sobre validez del contrato.

Para el solo efecto de claridad expositiva denominaré "concurso horizontal" a aquella situación en la que se trata de reglas generales y especiales de tutela del acreedor y "concurso vertical" a aquellas situación en las que se trata de normas de tutela y de validez.

Aunque, desde luego, haya algo de arbitrario en esta denominación, lo que quiero significar en ella es que las normas generales y especiales operan en un mismo nivel: el de las consecuencias del incumplimiento contractual. En cambio, al compararlas con las de validez, advertimos que se desenvuelven en niveles distintos: unas respecto al incumplimiento y otras respecto a la validez del contrato.

Pues bien, advertido lo anterior, resulta necesario precisar las situaciones de concurso que voy a considerar aquí. Tratándose de concursos horizontales, me detendré en la situación de la acción resolutoria del artículo 1489 y la rescisoria propia del régimen de los vicios redhibitorios y en las acciones indemnizatorias. Tratándose de concursos verticales, me ocupará, por una parte, la convivencia de la acción de nulidad por error con la resolutoria y de la primera con la rescisoria propia de los vicios redhibitorios y, por otra parte, consideraré la situación del artículo 1814.

\section{Diversos concursos de tutelas.}

a) Resolución y vicios redhibitorios. La pregunta desde la cual debemos comenzar es la siguiente: ¿puede ser que las mismas circunstancias configuren el supuesto de hecho de la acción resolutoria del artículo 1489 
y el supuesto de hecho de la acción rescisoria propia de la disciplina de los vicios redhibitorios?

En principio, la respuesta exigiría prestar cuidadosa atención al supuesto de hecho de los vicios redhibitorios y al de la resolución. Sin embargo, esta tarea no resulta indispensable aquí. La doctrina se ha preocupado de ambas $\operatorname{cosas}^{11}$ y las vacilaciones que ha manifestado al respecto no enturbian la posibilidad de concurso. Con todo, allí donde resulta necesario, se considerarán ciertos aspectos de los respectivos supuestos de hecho.

Probablemente haremos bien en avanzar por otra dirección que consiste en mostrar que la presencia de un vicio redhibitorio en la cosa configura lo que puede denominarse una "entrega imperfecta" y que, atendida la gravedad del defecto exigida por el artículo 1858 se trataría, en principio de un incumplimiento resolutorio.

Estas afirmaciones exigen cierta prueba. En otro lugar me he dedicado a examinar con mayor atención las entregas imperfectas ${ }^{12}$, de manera que aquí bastará una somera mención.

Una sencilla taxonomía del incumplimiento nos enseña que éste puede consistir en la ausencia completa de la prestación, en su realización tardía o en una realización defectuosa. En segundo lugar, la realización defectuosa será aquella que no logra satisfacer el interés del acreedor protegido por el contrato. A continuación, tratándose del contrato de compraventa, Alessandri Rodríguez señaló: "[...] el vendedor se obliga a poner al comprador en posesión útil y pacífica de la cosa vendida"13. En cuarto lugar, entonces, habrá que concluir que la entrega de una cosa con vicios configura un cumplimiento imperfecto pues parte del interés del acreedor garantizado por el contrato (la posesión útil) se ha frustrado.

La entrega de una cosa con vicios constituye, entonces, una entrega imperfecta, es decir, un incumplimiento del vendedor. Ahora, es necesario

${ }^{11}$ Con respecto a la acción resolutoria puede consultarse Vidal Olivares, Álvaro, El incumplimiento resolutorio en el Código Civil. Condiciones de procedencia de la resolución por incumplimiento, en PizARro Carlos (coordinador), Estudios de Derecho Civil (Santiago, LegalPublishing, 2009), IV. Si bien es cierto que se trata de un texto que asume una de las posturas posibles, además de su innegable mérito intelectual, la ventaja es que contiene antecedentes y copiosa información bibliográfica respecto de las demás. Con respecto a los vicios redhibitorios, los trabajos más comprensivos son Oviedo Albán, Jorge, Sobre el concepto de vicio redhibitorio en la compraventa. Análisis comparado de la jurisprudencia chilena y colombiana, Revista Chilena de Derecho, 37 (2010) 2; y Oviedo AlBáN, Jorge, La garantía por vicios ocultos en la compraventa (tesis doctoral, Santiago, Universidad de los Andes, 2012), pp. 73-140.

${ }^{12}$ De la Maza, I., cit. (n. 3).

${ }^{13}$ Alessandri, A., De la compraventa, cit. (n. 10), p. 659. 
determinar si ese incumplimiento, en principio, satisface las condiciones de procedencia del artículo 1489.

De esas condiciones, la que resulta relevante aquí es el carácter esencial del incumplimiento ${ }^{14}$. No cualquier incumplimiento faculta a resolver el contrato, sino, nada más aquel que resulta suficientemente grave ¿Cuándo podremos predicar gravedad de un incumplimiento? En el ámbito nacional, Claudia Mejías ha prestado particular atención a este tema, llegando a la conclusión de que es posible derivar de diversas disposiciones del Código Civil manifestaciones de la gravedad del incumplimiento ${ }^{15}$. Señala esta autora que el incumplimiento será grave: $i$ ) cuando así lo hayan determinado las partes expresa o implícitamente; $i$ ) cuando frustre el propósito práctico perseguido por el acreedor; y iii) cuando determine que el acreedor pierda la confianza en el futuro cumplimiento del deudor.

No necesitamos ahondar demasiado en estos criterios. Quizás, sin embargo, convenga detenerse por un momento en la noción de "propósito práctico" del contrato, de uso cada vez más frecuente en nuestra doctrina. Se trata de una noción acuñada por Federico de Castro y cuya presentación más acabada ha corrido de cargo de Antonio Manuel Morales Moreno ${ }^{16}$. Siguiendo las ideas de este último autor, podríamos, entonces, decir que propósito práctico corresponde al interés de las partes protegido por el contrato.

Pues bien, la idea que quiero señalar es que tratándose de un vicio redhibitorio que autorice el recurso a la acción rescisoria siempre se satisface el requisito de gravedad propio del incumplimiento resolutorio, pues resulta ser el caso que necesariamente se frustra el propósito práctico asegurado por el contrato.

Creo que lo anterior debería ser aceptado de manera más bien pacífica, y la razón es suficientemente evidente. En su numeral segundo, el artículo 1858 exige la gravedad del vicio en los siguientes términos: "Ser tales, que por ellos la cosa vendida no sirva para su uso natural, o sólo sirva imperfectamente, de manera que sea de presumir que conociéndolos el comprador no la hubiera comprado o la hubiera comprado a mucho menor precio".

Por su parte, Jorge Oviedo, comentando este precepto indica: "En la jurisprudencia de Chile y Colombia de manera coincidente se ha calificado también al vicio como grave en la medida en que el defecto impida o reduzca

${ }^{14}$ Una condición que, a estas alturas, nadie niega. Véase, en general: MEjías Alonzo, Claudia, El incumplimiento que faculta a resolver el contrato a la luz de las disposiciones del Código Civil, en De la MAZA, IÑIgo (coordinador), Incumplimiento contractual: nuevas perspectivas (Cuadernos de Análisis Jurídicos, Colección de Derecho Privado VII, Santiago, Universidad Diego Portales, 2011).

${ }^{15}$ Mejías, C., cit. (n. 14), pp. 188-211.

${ }^{16}$ Morales Moreno, A. M., cit. (1983) pp. 1529-1546. 
el uso de la cosa (normal o convenido), de tal forma que la gravedad se mide desde la inidoneidad o ineptitud que genere en ella" ${ }^{17}$.

Estas citas deberían resultar suficientes para aguantar la conclusión: cada vez que se califica un vicio como redhibitorio se satisface el requisito de gravedad que exige el incumplimiento resolutorio pues iqué duda puede cabe acerca de que esa gravedad frustra el propósito práctico?

En síntesis: existe concurso; las mismas circunstancias que configuran el supuesto de hecho de los vicios redhibitorios configuran el supuesto de hecho de la acción resolutoria.

Si esto es correcto surge, sin embargo, una pregunta epor qué en la sentencia de 27 de julio de 2005 la Corte Suprema consideró que las circunstancias configuraban el supuesto de hecho de la acción resolutoria, pero no el de la redhibitoria? Para responder a esta pregunta, comencemos recordando el considerando $7^{\circ}$ de esa sentencia, según el cual: "[...] de acuerdo a las disposiciones que reglamentan la institución de los vicios ocultos, ellas se aplican cuando entregada la cosa realmente vendida, ésta resulta tener un vicio existente al tiempo de la venta, pero que no puede ser advertido por el comprador, lo que en este caso se cumple, como se encuentra establecido en autos. Pero ello sólo puede tener lugar cuando la cosa entregada es realmente la vendida, lo que no acontece en autos, donde la cosa entregada es otra, como ha quedado establecido en la sentencia de primer grado.

No existen vicios redhibitorios, pues, cuando lo entregado fue otra cosa. El razonamiento parece correcto. Sin embargo, al extremarlo, llegamos a una conclusión contra intuitiva, pero también correcta.

No existen vicios redhibitorios cuando lo entregado es algo distinto a lo que se debe. Por lo tanto, la primera pregunta habrá de ser qué es lo que se debe. Tratándose de obligaciones de especie o cuerpo cierto la cosa debida es únicamente la designada; por lo mismo, no se puede cumplir con otra, planteándose, en verdad, una especie de supuesto de imposibilidad que se resuelve a través de los vicios redhibitorios ${ }^{18}$. En las obligaciones de género, sin embargo, la cosa no se individualiza; lo que se debe ex artículo 1509 es un individuo indeterminado del género de calidad a lo menos mediana. De esta manera, cada vez que se entrega un individuo del género de calidad inferior a la mediana no hay -siguiendo el razonamiento de la Corte Suprema en esta sentencia- un supuesto de vicio redhibitorio, sino la entrega de una cosa distinta a la debida. Esta idea que puede desprenderse de la sentencia

${ }^{17}$ Oviedo Albán, J., cit. (n. 6), p. 110.

${ }^{18}$ Sobre esta idea véase: Morales Moreno, Antonio Manuel, Tres modelos de vinculación del vendedor en las cualidades de la cosa, en Anuario de Derecho Civil, 65 (2012) 1, pp. 9-10. También: Verda y Beamonte, José Ramón, Saneamiento poir vicios ocultos. Las acciones edilicias (Bogotá, Universidad del Rosario, 2009), p. 280. 
en comento, ha sido lúcidamente expuesta por Verda y Beamonte en los siguientes términos: "La obligación de saneamiento se aplica, exclusivamente, en el ámbito de la venta de cosa específica, atribuyendo al vendedor el riesgo de que en dicha cosa existiera un vicio oculto al tiempo de la celebración del contrato. Dado que en esta clase de contratos, el vendedor que pone en poder y disposición del comprador la cosa vendida qualis erat en el momento de perfeccionarse el contrato cumple regularmente la obligación de entrega, no pueden ejercitarse contra él las acciones de incumplimiento. Sin embargo, el comprador de la cosa defectuosa tendrá a su disposición las acciones edilicias [...]. La obligación de saneamiento no se aplica, en cambio, en el ámbito de la cosa genérica, donde el vendedor sólo cumple correctamente la obligación de entrega cuando pone en poder y disposición del comprador una cosa en la que concurren todas las cualidades previstas en el contrato o presupuestas por las partes. Por lo tanto, si en la cosa entregada falta alguna de dichas cualidades, las acciones pertinentes, no serán las edilicias, sino las de incumplimiento $[\ldots]^{19}$.

b) Indemnización: normas generales y especiales. Como se recordará, en el caso resuelto por la sentencia de 31 de octubre de 2010, la demandada buscó enervar la pretensión indemnizatoria señalando que la acción indemnizatoria era la propia de los vicios redhibitorios y que había prescrito. El Tribunal despejó la cuestión señalando que no era esa acción indemnizatoria, sino la general derivada del incumplimiento ex artículos 1489 y 1826. Sin embargo, esto deja pendiente la cuestión del concurso.

Desde luego, una posibilidad consiste en sostener que aquí no habían existido vicios redhibitorios, por lo mismo, el concurso entre sus acciones indemnizatorias no llegó a producirse ${ }^{20}$. Sin embargo, el carácter sinuoso que mantienen las fronteras que delimitan el campo operativo de los vicios redhibitorios en Chile justifica tratar el caso como si pudiera ser de vicios redhibitorios. Particularmente porque como ha sugerido Oviedo Albán, en un estudio sobre la materia: “[...] podemos indicar que en el análisis de los fallos hay dos elementos concurrentes: el primero es la presencia en el bien de un defecto consistente en la insuficiencia técnica o material y el segundo, que como consecuencia de ello el bien no sea idóneo para producir el resultado

${ }^{19}$ VeRda y BeAmonte, cit. (n. 18), p. 280. Una presentación más general del estado de la cuestión en la doctrina puede encontrarse en Oviedo AlBán, J., cit. (n. 6), pp. 264-273.

${ }^{20}$ Así, siguiendo la práctica francesa, podríamos considerar que cuando las partes pactan la cualidad, su ausencia no determina la existencia de un vicio redhibitorio, sino de una disconformidad de la cosa entregada que se resuelve con cargo a las normas de la obligación de entrega. Sobre el tema puede consultarse Verda y Beamonte, cit. (n. 18), pp. 56-57. 
natural o el que el comprador espera y hace saber al vendedor al momento de celebración del contrato, a partir de todo lo cual tanto los tribunales chilenos como colombianos concluyen que el bien adolece de un vicio redhibitorio"21.

Comenzaré por la acción general de daños. Para considerarla, probablemente resulte útil recordar que una de las defensas de la demandada frente a la pretensión indemnizatoria consistió en cuestionar el carácter autónomo de la acción de daños ${ }^{22}$. Por lo mismo, una cuestión que se suscita respecto a la procedencia de esta acción se refiere, precisamente, a parte de su supuesto de hecho y consiste en determinar si se puede interponer autónomamente o, en cambio, es necesario aparejarla a una de cumplimiento forzado o resolutoria.

La opinión de la Corte Suprema en este caso es que, al menos bajos las circunstancias en que se planteó la acción, la pretensión resarcitoria es independiente. Así se lee del considerando decimocuarto de su decisión, en los siguientes términos: "Que tampoco se hará lugar a la alegación de la demandada en el sentido que la acción de daños y perjuicios intentada no está asociada a una acción de cumplimento o de resolución contractual, lo que vulneraría los dispuesto en los artículos 1489 y 1873 del Código Civil. En efecto, debe rechazarse esta alegación, de acuerdo con lo reflexionado en los considerandos noveno y décimo de esta sentencia de reemplazo".

Por su parte, los considerandos citados señalan lo siguiente: " $9^{\circ}$ Una vez establecido que efectivamente ha existido un incumplimiento del contrato, corresponde determinar si la actora ha podido ejercer la acción indemnizatoria, como lo ha hecho, prescindiendo de lo que disponen los articulos 1489 y 1826 del Código Civil, que parecen indicar que tal acción no es autónoma, sino que debe siempre ir acompañada sea de la petición de resolución contractual o bien de la exigencia de cumplimiento del contrato. Como ya lo ha resuelto esta Corte en otras oportunidades, y siguiendo una moderna tendencia doctrinal (rol 3.341-012), se estima que, en este caso, la demandante ha podido plantear su demanda de responsabilidad civil contractual, sin asociarla a la resolución del contrato, pues, la entrega material de los rodillos está cumplida y parte de ellos fueron cortados". Y " $10^{\circ}$ Que, en todo caso, una demanda de daños y perjuicios en los términos que se han descrito, debe ser considerada como parte de lo que el vendedor debe en 'cumplimiento del contrato', de acuerdo con los términos del artículo 1489 del Código Civil. En efecto, conforme con el artículo 1591, 'el pago total de la deuda comprende el de los intereses e indemnizaciones que se deban'. Dado que en este juicio se pretenden indemnizaciones derivadas de un incumplimiento contractual, asociadas a una entrega imperfecta de la cosa

${ }^{21}$ Oviedo Albán, J., cit. (n. 11), p. 249.

${ }^{22}$ La demandante no solicitó ni el cumplimiento forzado ni la resolución del contrato. 
vendida, debe entenderse que el deudor está ejerciendo una acción de cumplimiento contractual, para ser debidamente pagado por el deudor, aunque la acción esté reducida a las indemnizaciones que el actor estima que la sociedad demandada le adeuda por incumplimiento del contrato".

La Corte señala, pues, dos cosas. En el considerando $9^{\circ}$, establece que existe una cierta práctica de ese Tribunal de aceptar autónomamente la pretensión indemnizatoria; $\mathrm{y}$, en el décimo que esa práctica se encuentra respaldada por la doctrina. Ambas afirmaciones son correctas. Así, tratándose de las sentencias de la Corte Suprema, puede prestarse atención a la sentencia de 7 de diciembre de $2010^{23}$ y los elocuentes términos en que establece la autonomía de la pretensión indemnizatoria ${ }^{24}$. Por lo que toca a la doctrina,

23 "Eduardo Alfredo Opazo Lamana y otros con Inmunomédica Laboratorio Limitada" (2010)

${ }^{24}$ En los siguientes términos: "14 Que sobre la materia no puede soslayarse que, conforme a los principios que integran el Código Civil, no se observan las particulares motivaciones que podrian inducir a privar a los afectados de dirigir las acciones en la forma y del modo como mejor se ajusten a sus intereses, desde el momento que el derecho civil otorga a las personas el principio de libre disposición de sus bienes y autonomia de la voluntad, todo lo cual lleva a reconocer las mayores prerrogativas al momento de someter las pretensiones al órgano jurisdiccional. Es por lo anterior que esta Corte Suprema ha reconocido la independencia y autonomía de las acciones indemnizatorias, sean estas moratorias o perentorias, las que cualquiera sea la naturaleza del objeto de la prestación, pueden impetrarse en forma, exclusiva, desde el momento que el legislador ha establecido su procedencia y la forma más usual de interposición; pero no ha probibido la que en mejor forma repare integralmente el daño derivado del incumplimiento./ En efecto, la acción indemnizatoria no se encuentra ligada únicamente en sede contractual a la resolución o cumplimiento forzado de lo pactado, puede entonces cobrar identidad propia, como acción principal, aunque asociada a una de las variantes referidas resolución o cumplimiento forzado, como a ninguna de ellas, sin perjuicio que para ponderar esta pretensión resulta indispensable vincularla con el hecho en que se le hace descansar./ Entonces ante la entidad independiente que la ley prevé en general, no existen razones para vincularla de manera determinante con cada una de aquellas acciones de resolución y cumplimiento, como tampoco para entenderla accesoria a las mismas, en especial cuando se reclama la reparación de daños morales. Una razón fundamental surge para ello: tanto la teoría clásica, al considerar que la indemnización es la misma obligación cuyo cumplimiento se logra por medio de la justicia en naturaleza o por equivalencia, corno por la teoría moderna que indica que la indemnización es una nueva obligación, lo que permite arribar a la conclusión que se trata de una obligación principal, nunca accesoria./ En sentido contrario, la interpretación exegética del artículo 1489 del Código Civil deriva de una lectura literal del mismo, se contrapone a la reparación integral del acreedor. 'La indemnización permite colmar toda aquélla parte del interés del acreedor insatisfecho por causa de incumplimiento, a la que los otros remedios no llegan o no pueden llegar, permitiendo así la realización del interés del acreedor en la prestación, afectada por el incumplimiento' (VIDAL, Álvaro, La protección del comprador: Régimen de la Convención de Viena y su contraste con el Código Civil, Edit. Universitarias de Valparaíso, pág. 198); $15^{\circ}$ Que en este mismo sentido la profesora Patricia López Díaz, 
hasta donde llegan mis noticias, el trabajo más ambicioso y logrado en la materia, de la profesora Patricia López, defiende esta misma idea ${ }^{25}$.

La segunda idea que desenvuelve la Corte es que, con cargo al artículo 1591, en verdad, esta pretensión indemnizatoria sería una de cumplimiento ${ }^{26}$.

Con todo, y a efectos de estas páginas, todo indica que el supuesto de hecho de la acción de daños se ha cumplido. Ahora será necesario desplazarse al de la acción de daños derivado de la presencia de vicios redhibitorios.

La pregunta que es necesario formularse resulta semejante a la anterior, es decir, se refiere a la independencia de la pretensión indemnizatoria cuando su justificación se presenta en la existencia de vicios redhibitorios. Se trata - como también sucedía en el tema anterior- de una cuestión debatida ${ }^{27}$. Para presentarla brevemente, habrá que comenzar advirtiendo que la discusión

en su publicación sobre 'La indemnización compensatoria por incumplimiento de los contratos bilaterales como remedio autónomo en el Derecho Civil Chileno' (Revista Chilena de Derecho Privado No 15, en prensa) sostiene: 'Un segundo enfoque para abordar dicha autonomia, consiste en sostener que el acreedor opta por demandar directamente la indemnización de los perjuicios derivados del incumplimiento del contrato, con el sólo propósito de alcanzar la indemnización plena. El acreedor no podría obtener tal indemnización si demandara el cumplimiento forzado del contrato pues no existirian perjuicios por incumplimiento compensatorio o la resolución dado que en este caso la indemnización tendría el carácter de complementaria, de modo que no abarcaria todos los perjuicios derivados del incumplimiento'. Continúa señalando que 'el ejercicio de la acción indemnizatoria implica la renuncia al cumplimiento forzado o a la resolución del contrato. La indemnización se presenta entonces como un remedio autónomo, cualquiera sea la forma en que se ejecute la obligación; la única diferencia es el efecto inmediato derivado de la indemnización, toda vez que si se trata de un contrato de tracto sucesivo permite al acreedor seguir vinculado jurídicamente al deudor, una vez que éste le indemnice los perjuicios; y si el contrato es de ejecución instantánea o ejecución diferida conlleva la extinción del contrato efecto que el acreedor ha asumido, y por consiguiente, le resulta irrelevante'. Nótese que tal extinción del contrato no equivale a la resolución, dado que si asi fuera la indemnización de perjuicios sería complementaria y no plena. Esta es, por tanto, la forma correcta de entender la autonomia indemnizatoria por incumplimiento de un contrato bilateral".

${ }^{25}$ López DíAz, Patricia, La indemnización compensatoria por incumplimiento de los contratos bilaterales como remedio autónomo en el derecho civil chileno, en Revista Chilena de Derecho Privado Fernando Fueyo Laneri, 15 (julio de 2010). El correcto trabajo de la profesora López no debería, sin embargo, ocultar la abundante doctrina que ha opinado lo contrario (citada en dicho trabajo). Con todo, en mi opinión al menos, ninguno de los otros trabajos se toma tan en serio el tema como el de la profesora LópEz.

${ }^{26}$ Esta idea es desarrollada en De la Maza Gazmuri, Iñigo - Vidal olivares, Álvaro, Propósito práctico, incumplimiento contractual y remedios del acreedor: Con ocasión de tres recientes sentencias de la Corte Suprema, en Ius et Praxis, 20 (2014) 1, pp. 15-37.

${ }^{27}$ El debate se encuentra bien expuesto en GUZMÁn BRITO, Alejandro, Sobre la relación entre las acciones de saneamiento de los vicios redhibitorios y las acciones comunes de 
respecto de la autonomía de la pretensión indemnizatoria únicamente se presenta respecto del artículo 1861 y no de los artículos 1867 y 1868 . Y la pregunta es si la acción de daños del 1861 puede ejercerse con independencia de la acción redhibitoria. Una vez más -y, no obstante las opiniones en contra- doctrina especialmente autorizada y algunas opiniones recientes de nuestros tribunales de justicia parecen mostrar que la pretensión indemnizatoria es autónoma ${ }^{28}$.

En principio, entonces, diremos que resulta perfectamente factible el concurso entre la acción indemnizatoria de carácter general y aquella derivada de los vicios redhibitorios.

c) El error y la acción resolutoria. ¿Pueden configurar las mismas circunstancias los supuestos de hecho del error con trascendencia anulatoria y de la acción resolutoria? En otra parte me he ocupado con suficiente detalle de esta cuestión ${ }^{29}$, por lo mismo, aquí puede ser presentada en términos más resumidos.

El quid de la cuestión parece encontrarse en determinar si resulta posible que los defectos que autorizan el recurso al régimen del error pueden, además, concebirse como parte del supuesto de hecho de la acción resolutoria.

La respuesta, en mi opinión, es que sí. Ello se desprende, desde luego, de la sentencia de 27 de julio de 2005 . Igualmente podemos servirnos de la comparación de un caso resuelto por la Corte Suprema con fecha 19 de enero de $2010^{30}$ y la opinión de Alessandri Besa ${ }^{31}$. Por lo que toca a la sentencia, se trata de un caso en el cual la Corte Suprema conoce de una compraventa de camiones en las cuales se había establecido su año de fabricación (2000 y 2001) y, sin embargo, los vehículos que se entregaron habían sido fabricados en otra fecha (1997 y 1998). La Corte estimó que el año de fabricación constituía una cualidad esencial según lo dispuesto en el artículo 1454 y que, por lo tanto, si había existido error sobre ella el contrato debía anularse.

Sobre este caso resulta importante advertir que la cualidad del vehículo

indemnización, con especial referencia a su prescripción (Opinión profesional), en Revista Chilena de Derecho Privado, 9 (2007).

${ }^{28}$ Por lo que toca a la doctrina puede consultarse Guzmán, A., cit. (n. 27); y OviEDo AlbÁn, J., cit. (n. 11). En lo que se refiere a los tribunales superiores de justicia puede consultarse "Rosario Larzabal Beraza con Sociedad Inmobiliaria Talasia Limitada" (2008) y "Supermercado de Materiales de la Construcción Limitada contra Empresa Constructora de Viviendas Económicas Diez, Luengo, Weil” (2010).

${ }^{29}$ De la Maza, I., cit. (n. 8).

30 "Consorcio de Trasportes Trancura Limitada contra Tocale Tuna, Romilio Perfecto" (2010)

${ }^{31}$ Alessandri Besa, Arturo, La nulidady la rescisión en el derecho civil chileno ( $3^{\mathrm{a}}$ edición, Santiago, Editorial Jurídica de Chile, 2008), II. 
había sido establecida en el contrato y si se aceptó que era una cualidad esencial establecida en el contrato puede, a la vez señalarse que la falta de ella configuraría el supuesto de hecho de la acción resolutoria. Sobre este último punto podemos acudir a la opinión de Alessandri Besa: "El error sobre una cualidad accidental de la cosa, que una de las partes ha elevado a la categoría de motivo determinante del contrato, no debe confundirse con la situación que se presenta cuando una de ellas pone como condición que la cosa sobre la que versa el contrato tenga una calidad determinante, y la otra acepta el contrato en estos términos. En este segundo caso, la existencia de esa calidad en la cosa objeto del contrato es una de las estipulaciones del mismo, de modo que si la cosa no la contiene, no hay error sustancial, sino que incumplimiento del contrato por una de las partes. El efecto es, entonces, la resolución del contrato, o su cumplimiento forzado, con indemnización de perjuicios (siempre que se trate de un contrato bilateral), en vez de rescisión del mismo"32.

Desde luego, el hecho de el autor se refiera a una cualidad accidental y la Corte Suprema a una esencial resulta irrelevante. Lo realmente determinante es que, en opinión de Alessandri Besa el caso del camión configura un supuesto de incumplimiento resolutorio.

Lo segundo que afirma el autor ya no se refiere al concurso, sino a la forma de resolverlo. En su opinión, la acción resolutoria desplazaría a la de nulidad por error. Volveré sobre esta cuestión al considerar la forma en que han de resolverse los concursos en la tercera parte de este trabajo.

d) El error y los vicios redhibitorios. Verday Beamonte señala: "En la doctrina científica española clásica ha sido frecuente explicar el régimen de responsabilidad del vendedor [por vicios redhibitorios] como una concreta aplicación de la doctrina del error en sede de compraventa"33.

Algo semejante es posible afirmar respecto del ámbito nacional. Así, por ejemplo, Jorge Baraona González, haciendo pie en el artículo 1858, establece una conexión entre el vicio redhibitorio y el error, toda vez que el primero exige una cierta ignorancia del comprador que configura al segundo ${ }^{34}$. En un sentido semejante y más explícitamente, Caprile Biermann dice: “[...] restaría una interrogante: cuando la cosa individualizada no funciona bien, ¿̨no habría, entonces, un error respecto de sus calidades substanciales? Nosotros creemos que tanto la nulidad por error vicio del consentimiento como las acciones edilicias sancionan la incorrecta apreciación de las calidades de la cosa individualizada -cuerpo cierto- que se presenta en el momento de la

${ }^{32}$ Ibíd., p. 33.

${ }^{33}$ Verda y Beamonte, J. R., cit. (n. 18) p. 235.

${ }^{34}$ BARAONa González, Jorge, La acción redhibitoria como acción de nulidad, en Estudios de Derecho Civil (Santiago, LegalPublishing, 2008), III, pp. 660-661. 
celebración del contrato y se manifiesta luego en el periodo de ejecución; por esa razón, al parecer don Andrés Bello se sirvió de la palabra 'rescisión' y no 'resolución' para denominar la sanción propia de la acción redhibitoria"35.

En fin, a la misma posición, me parece, llega Jorge Oviedo Albán luego de una cuidadosa reflexión acerca de las distintas opiniones de los autores que a nivel nacional y comparado concluyendo que los supuestos de hecho coinciden $^{36}$.

La cuestión, entonces, parece ser pacífica en la doctrina: el mismo supuesto de hecho que configura el error vicio del consentimiento puede configurar el supuesto de hecho de la acción rescisoria propia de la disciplina de los vicios redhibitorios ${ }^{37}$.

e) El artículo 1814. Como ya ha quedado dicho, en el caso que concluyó con la sentencia de 31 de octubre de 2012, la juez de primera instancia concedió la indemnización de daños justificándola en el artículo 1814. Dicha sentencia fue confirmada por la Corte de Apelaciones y revertida por la Corte Suprema. La razón por la cual la Corte revirtió las sentencias es de carácter formal. En palabras del Tribunal: "De lo expuesto es claro que ninguna de las hipótesis de hecho que se describen en esta norma, y que ha servido para fundar el fallo, encaja con los fundamentos con que el demandante apoya su demanda, que, como se ha dicho, asumen que se trata de un contrato válido, sin pedirse la nulidad o resolución de [sic por 'del'] mismo". De ahí, entonces, la ultra petita que justificó la casación en la forma. Sin embargo, lo interesante consiste en considerar si las circunstancias del caso correspondían al supuesto de hecho del inciso segundo del artículo 1814 y si éste entra en concurso con las demás medidas de tutela ya consideradas.

Lo que exige el precepto en cuestión es que falte una parte considerable

${ }^{35}$ Caprile Biermann, Bruno, Las acciones del comprador insatisfecho: el cúmulo actual (ley de protección al consumidor, vicios redhibitorios, error sustancial, resolución por incumplimiento) y la tendencia al deber de conformidad en el derecho comparado, en Mantilla Espinosa Fabricio - Pizarro Wilson, Carlos (coordinadores), Estudios de Derecho privado en homenaje a Christián Larroumet (Santiago, Fundación Fueyo - Universidad Diego Portales, 2008), p. 323.

${ }^{36}$ Oviedo, J., cit. (n. 11), pp. 179-203.

${ }^{37}$ Refiriéndose al derecho francés Goldie-Genicon, Charlotte, Contribution à l'étude des rapports entre le droit commun et le droit spécial des contrats (Paris, Librairie Général de Législation et Jurisprudence, 2009), pp. 514-515, asume que es posible que exista un vicio redhibitorio sin que esto afecte a la voluntad del comprador. En teoría puede ser, aunque resulta difícil de imaginar. Se trataría de un caso en el que la cosa adolece de un defecto ignorado por el comprador que la inhabilita para su uso natural, pero que, sin embargo, no vicia la voluntad del comprador ¿Qué quiere decir eso, que, de haber conocido el defecto, el comprador hubiese adquirido la cosa igualmente en los mismos términos? Realmente es difícil de imaginar un caso así. 
de la cosa al momento de perfeccionarse el contrato. Lo que muestran, sin embargo, las fuentes históricas -el Digestum y las Partidas- es que el supuesto de hecho de la norma es uno de pérdida o deterioro parcial, no uno en el que la cosa nunca tuvo las características que se echan en falta ${ }^{38}$. Sin embargo, al menos en una ocasión los tribunales superiores chilenos han utilizado el precepto para resolver un caso de una cosa que, simplemente carecía de una cualidad asegurada en el contrato. Se trata de la sentencia de la Corte de Apelaciones de Valdivia de 5 de diciembre de $2009^{39}$. En los hechos se demandó la rebaja del precio ex artículo 1.814 toda vez que lo vendido -un vuelo forestal de pino de Oregón- correspondía a 13,3 hectáreas aproximadas y lo que se entregó fueron 8,6. Convendrá prestar atención a un par de considerandos de la sentencia en cuestión: " $10^{\circ}$ Que una diferencia de envergadura, para hacer operar el mecanismo de rebaja del precio del articulo 1814, debe ser 'considerable'. Conforme al Diccionario de la Real Academia Española 'considerable' es 'digno de consideración' o 'suficientemente grande, cuantioso o importante'. Se trata, pues, de uno de esos conceptos legales de contenido indeterminado que corresponde a la judicatura precisar en el caso concreto. Respecto de una compraventa de predios forestales, en que las partes pactaron la cabida del todo "aproximado", resultaría dudosa una diferencia de entre un 10 y 20 por ciento, pero no cabe duda que una diferencia de más del 30 por ciento debe reputarse considerable, atendidos los márgenes de utilidad esperables del negocio, que se ven radicalmente afectados en un caso y en otro. Y por cierto, tampoco resultaría dudosa una diferencia menor al $10 \%$, porque seguramente ella quedaría cubierta por la "aproximación" en la determinación del objeto". Se añade: " $11^{\circ}$ Que en tales condiciones, no cabe sino concluir que en el contrato de autos efectivamente faltaba, de modo objetivo, una parte considerable del objeto que se suponia existir, y ello bace que deba hacerse lugar a la demanda de rebaja del precio, según se dirá en lo resolutivo de esta sentencia".

$\mathrm{Al}$ considerar estos párrafos aprendemos dos cosas interesantes. La primera de ella es que el deterioro o falta se obtiene no de comparar la cosa tal y como era y aquella que se entregó; sino la cosa tal y como se pactó en el contrato y aquella que se entregó. La segunda cosa a la que conviene prestarle atención es que "considerable" es un concepto que debe precisarse en el caso concreto y que más del $30 \%$ de diferencia cuando se trata de un terreno, es considerable.

Pues bien, si eso resulta correcto, entonces, en el fondo al menos, la juez

\footnotetext{
${ }^{38}$ Alessandri Rodríguez, A., De la compraventa, cit. (n. 10), p. 203.

39 "Contra Municipalidad de Futrono" (2009).
} 
de primera instancia -al margen de la ultra petita - no andaba desencaminada al incardinar los hechos en el inciso final del artículo 1814.

Ahora podemos considerar los otros mecanismos de tutela del acreedor. Desde luego, no es necesario abundar sobre la acción general de indemnización de daños pues a ella ya se ha hecho referencia y con cargo a la misma falló la Corte Suprema ${ }^{40}$. Por lo que toca a la acción resolutoria, todo indica que se trataría de un incumplimiento grave pues, como ya ha quedado dicho, la concentración de níquel era el principal motivo que indujo a contratar a la compradora. Probablemente, el hecho de que haya sido la principal cualidad de la cosa y que la compradora haya ignorado su ausencia nos indica que también se satisface el supuesto de hecho de la acción de nulidad por error. Finalmente, respecto de los vicios redhibitorios, aceptando que se trata de un vicio de composición, se satisfaría su supuesto de hecho.

Esta es, entonces, la situación respecto al inciso segundo del artículo 1814. Si mantenemos fidelidad a las fuentes históricas, en el caso del níquel no se satisface el supuesto de hecho de ese artículo (no es que a la cosa le falte una parte, es que nunca la tuvo). $\mathrm{Si}$, en cambio, aplicamos dicho precepto como, en al menos una ocasión, lo han hecho nuestros tribunales superiores de justicia, una vez más, entonces, nos encontramos frente a la presencia de un concurso.

\section{Sintesis.}

En esta parte del trabajo me ha interesado mostrar cómo se producen concursos entre los distintos medios de tutela a través de los cuales el comprador puede incardinar sus pretensiones. He señalado, además, que esos concursos pueden ser horizontales (entre normas generales y especiales de incumplimiento) o verticales (entre estos tipos de normas y aquellas de validez). Finalmente, sin ánimo exhaustivo, he presentado algunos de esos concursos, advirtiendo que las mismas circunstancias pueden configurar el supuesto de hecho de la acción resolutoria, de la acción redhibitoria, de la acción general de daños, de la acción indemnizatoria propia de la acción reivindicatoria, de la acción de nulidad por error y, en fin, de las acciones derivadas del inciso segundo del artículo 1814.

\footnotetext{
${ }^{40}$ Con todo, un punto es interesante. El supuesto de hecho de la acción de daños propia del artículo 1814 resulta más exigente que el de la acción general de daños. El primero exige que se haya vendido "a sabiendas". Respecto del segundo, si bien es cierto que en Chile suele considerarse que requiere algún tipo de imputación al vendedor, éste no se limita a una hipótesis de dolo.
} 


\section{IV. ¿CÓMO SE RESUELVEN LOS CONCURSOS DE TUTELA?}

Responder a la pregunta de cómo se resuelven los concursos de tutela es el tema de la presente parte de este trabajo.

Para enfrentarla, haremos bien en servirnos de la distinción ya presentada entre concursos horizontales y verticales. Tratándose de los primeros, nuestra atención ha de dirigirse a la situación de concurso entre acción redhibitoria y acción resolutoria, de una parte, $y$, de otra, al concurso entre la acción de daños del artículo 1861 y aquella de carácter general. Por lo que toca a los concursos verticales, hemos de considerar aquel que se presenta entre acción resolutoria y error; y, en segundo lugar, el concurso entre vicios redhibitorios y error.

\section{Concursos horizontales.}

a) Entre la acción resolutoria y la acción redhibitoria. Ante todo, resultará útil advertir que la pregunta acerca de cómo ha de resolverse un concurso precisa que estemos frente a un concurso. La cuestión parece insultantemente obvia. La indico, simplemente, para recordar que, según lo dicho más arriba, para que nos encontremos frente a este tipo de concurso debe tratarse de una obligación de especie o cuerpo cierto o, podemos agregar ahora, de una genérica que se haya especificado ${ }^{41}$.

Pues bien, formulada la advertencia podemos continuar señalando que, en el ámbito nacional, no existe total acuerdo al respecto en la doctrina. Quizás, una primera prevención que resulte útil para explicar el desacuerdo a este respecto es que en la doctrina nacional tampoco existe acuerdo respecto a si la acción redhibitoria es rescisoria o resolutoria ${ }^{42}$.

La utilidad de esta prevención puede encontrarse en que, como se verá más adelante, si se acepta el carácter resolutorio de la acción redhibitoria, parece difícil no concluir que configuraría una norma especial respecto del régimen general de la resolución y entonces recibiría aplicación lo dispuesto en el artículo 13 CC. En cambio, si, como Baraona González, se estima que

${ }^{41}$ Así lo dice Fenoy Picon, Nieves, Falta de conformidad e incumplimiento en la compraventa. Evolución del ordenamiento español (Madrid, Colegio de Registradores de la Propiedad y Mercantiles de España, Centro de Estudios Registrales, 1996), p. 74: "[...] en la compraventa genérica, antes de la especificación, sólo puede afirmarse que el vendedor ha cumplido si entrega una cosa conforme al contrato. Los problemas que plantean las anomalías de la cosa encuentran solución en los remedios propios del incumplimiento. El límite de ese régimen se sitúa a partir de la especificación. En ese momento, por haberse transformado la obligación genérica del vendedor en específica (especificación), el comprador puede contar con las acciones edilicias".

${ }^{42}$ Sobre el particular una discusión muy correcta en CAPrile, B., cit. (n. 31), pp. 582-584. 
corresponde a una acción de nulidad este obstáculo desaparece y resulta posible afirmar que el comprador podría optar entre ejercer esa acción rescisoria o la acción resolutoria propia del régimen general del incumplimiento ${ }^{43}$.

La convivencia entre la disciplina del error y la acción resolutoria es una cuestión que ha de ocuparnos más adelante, por lo mismo, quiero considerar ahora que sucede si, como parecen entenderlo otros autores la acción redhibitoria posee un carácter resolutorio.

Así, por ejemplo, como resulta bien sabido, Alessandri Rodríguez criticó a Bello por el empleo de la expresión "rescisión” en la disciplina de los vicios redhibitorios y consideró que el término propio era "resolución" pues lo que había existido era el incumplimiento de una obligación del vendedor ${ }^{44}$. Desgraciadamente, este autor no extrajo las consecuencias que, para efectos del concurso, se desprendían de calificar de esa manera la acción redhibitoria.

Si lo hace, en cambio, una sentencia de la Corte de Apelaciones de San Miguel de 27 de enero de $2006^{45}$, que conoce de los reclamos de unos propietarios de unos departamentos canalizados a través de una acción quanti minoris en contra de la inmobiliaria que se los vendió. De manera más bien inexplicable, el tribunal de instancia declara resuelto el contrato, no obstante el hecho de que los demandantes no habían solicitado la resolución. La Corte de Apelaciones constata la evidente ultra petita. Sin embargo -y más bien obiter dictum - señala: "80 Que no cabe asimilar la obligación de saneamiento de los vicios redhibitorios, a una obligación derivada exclusivamente del objeto del contrato de compraventa, esto es una o más cosas que se trata de dar hacer o no hacer, según conceptúa el articulo 1460 del Código Civil, en este caso, las correlativas de entrega o tradición de la cosa y el pago del precio, de modo que su incumplimiento pudiere llegar a constituir la condición resolutoria tácita del artículo 1489 del mismo cuerpo legal, por cuanto el saneamiento de los vicios llamados redhibitorios está tratado especialmente en dicho Código y proporciona una acción distinta a la resolutoria, llamada redhibitoria, que como su nombre indica, Redhibir puede llevar al comprador a deshacer la venta según el derecho por no haberle manifestado el vendedor el defecto o gravamen de la cosa vendida (Diccionario de la Real Academia). Estos vicios en nuestro Código Civil, generan una acción diferente al comprador para que se deshaga (dice 'rescinda') la venta o para que se rebaje proporcionalmente el precio, según los articulos 1857 y siguientes. Ello está referido a la causa que lo llevó a contratar de la manera como lo hizo, toda vez que esta es el motivo que induce al acto o

${ }^{43}$ Baraona, J., cit. (N. 34) p. 665. En el mismo sentido Guzmán, A., cit. (n. 27), pp. 99-100.

${ }^{44}$ En particular, Alessandri Rodríguez, A., De la compraventa, cit. (n. 10), pp. 218.

45 "Mario Jara Carrasco y otros con Inmobiliaria San Francisco Limitada" (2006). 
contrato, según el artículo 1467 del mismo Código./De tal modo que ni siquiera un incumplimiento del saneamiento ni la indemnización de perjuicios que de ello se podría derivar, permite asimilar la acción deducida a una resolutoria tácita y su consecuente indemnización que autoriza el artículo 1489 del Código Civil, ya que el asunto es causal de una acción diferente, expresamente regulada en la compraventa que pudo o no ejercerse y que incluso los contratantes pudieron haber ampliado o restringido en su contrato (artículos 1859, 1863 y 1866 del mismo Código) pero que en caso de autos resultó ser solo la de rebaja del precio y la consiguiente indemnización de sus eventuales perjuicios derivados de haberse pagado un precio estimado excesivo./ En efecto, no es posible asumir que aun de existir vicios redhibitorios se estén causando perjuicios materiales, puesto que con una redhibición del contrato, devolviéndose la cosa y el total del precio o bien, mediante la adecuación, por rebajar, el precio de la compraventa, que es lo perseguido con la acción de autos, pueden quedar satisfechos y/o enervados dichos perjuicios materiales".

La Corte, aunque de manera algo ambigua, entiende, pues, que el contrato de compraventa posee una regulación especial frente al incumplimiento de la "obligación de saneamiento" y, por lo mismo, no procedería la acción resolutoria del artículo 1489.

En la medida en que se acepte el carácter resolutorio de la acción redhibitoria, la sentencia de la Corte recién transcrita hace sentido, ya que induce a aceptar que la entrega de una cosa con vicios redhibitorios constituye una especie de entrega imperfecta que ha sido especialmente regulada a través de la disciplina de los vicios redhibitorios. Si esto es correcto, la acción resolutoria del artículo 1489 configuraría el régimen general del incumplimiento de la obligación de entrega. Por su parte, la acción redhibitoria constituiría una regla especial aplicable a un supuesto particular de incumplimiento de la obligación de entrega, aquella en que la cosa presenta vicios redhibitorios. Siendo así, podría afirmarse que recibe aplicación la regla establecida en el artículo 13 CC.: la norma especial deroga a la general ${ }^{46}$.

Pues bien, como se ve, la forma de resolver el concurso entre la acción

${ }^{46}$ Ver Oviedo Albán, J., cit. (n. 11), pp. 309-310. Esto, por supuesto depende del estatus que se reconozca a la norma contenida en el artículo 13. Como ha sugerido Goldie-Genicon, CH., cit. (n. 37) pp. 447-510 las posibilidades son como una simple máxima de interpretación o como un principio general del Derecho; por otra parte, y siguiendo a la misma autora, resulta necesario determinar el sentido que hayamos de asignarle a la idea según la cual la norma especial deroga a la general. Como sea que fuera, en el derecho chileno, a diferencia del francés el adagio "specialia generalibus derogant" se encuentra en una norma jurídica, por lo mismo, las dudas que enfrenta Goldie-Genicon frente a su aplicación tienden a diluirse. Por otra parte, parece ser que en este caso si que se plantean las condiciones que configuran la antinomia que el artículo 13 permite resolver. 
redhibitoria y la acción resolutoria pasa por determinar si la primera es una acción de nulidad por error o una acción resolutoria especial ${ }^{47}$. Si sucede lo segundo, habremos de aceptar que el concurso se resuelve por desplazamiento: la regla especial desplaza a la general. Si, en cambio, aceptamos lo primero, tendremos que considerar como convive el error y la acción resolutoria. Tarea que nos ocupará más adelante.

Ahora bien, antes de abandonar este concurso, convendrá advertir que no resulta infrecuente que los tribunales resuelvan bajo las reglas de la resolución situaciones que quedan perfectamente cubiertas por la disciplina de los vicios redhibitorios sin siquiera plantearse la cuestión del concurso. Un ejemplo contribuirá a ilustrar la cuestión. Se trata de la sentencia de la Corte de Apelaciones de Santiago, de 20 de junio de $2010^{48}$. Carabineros de Chile dedujo acción de resolución por incumplimiento de contrato de compraventa en contra de una empresa encargada de elaborarle vestimenta basado en que dicha empresa no habría cumplido con los estándares de calidad señalados en el contrato ni procedió a reemplazar las piezas defectuosas. En particular, algunas piezas resultaban defectuosas en la medida en que la solidez del color no resultaba suficientemente resistente al sudor, lo que afectaría la presentación del usuario y podría transferir colorante a la piel. ¿Constituye eso un vicio redhibitorio? El número $2^{\circ}$ del artículo 1858 dispone que las imperfecciones de una cosa constituyen vicio redhibitorio cuando afectan a su uso natural, al uso que está destinada ordinariamente. Pues bien, los uniformes están, naturalmente, destinados a ser utilizados como vestimenta, en la medida que transmitan colorante la piel del usuario resulta más bien evidente que afectan a su uso natural ${ }^{49}$.

En el caso, sin embargo, el defecto se reclamó como incumplimiento contractual de conformidad al artículo 1489, es decir, no se acudió a la disciplina de los vicios redhibitorios, sino al incumplimiento de la obligación de entrega ${ }^{50}$. Por su parte, la Corte de Apelaciones consideró: “Que establecido el incumplimiento del contrato por parte de la demandada, de conformidad a

${ }^{47}$ Con todo, habrá que señalar que el profesor Gonzalo FigueroA YÁñEz, Rescisión, resolución y redhibición: ¿puede hablarse de un cúmulo de acciones, en ZÚNIGA Tejos, A. (coordinador) Estudios de derecho privado, Libro homenaje al jurista René Abeliuk Manasevich (Santiago, Editorial Jurídica de Chile, 2011), pp. 211-220, ha señalado no tener ninguna duda de que tratándose del concurso entre acciones resolutoria y rescisoria el comprador puede elegir. Sin embargo, no explica del todo por qué.

48 "Consejo de Defensa del Estado contra Desarrollo y Comercio S.A” (2009).

${ }^{49}$ En un sentido semejante Alessandri Rodríguez, A., De la compraventa, cit. (n. 10) II,1, p. 196, considera como vicio redhibitorio el que los barriles objeto del contrato comuniquen mal olor al vino.

${ }^{50}$ En el caso “Aquiles Spataris Schaffhauser con Sociedad Comercial Automotriz La Portada; Alejandro Luna Casas" (2005), frente a la presencia de vicios redhibitorios se demandó la resolución del contrato de compraventa. La vendedora consideró que 


\section{lo dispuesto en el artículo 1489 del Código Civil, procede declarar la resolución del mismo, como lo solicita la demandante".}

Como se ve, entonces, no existe una sola manera de resolver el concurso. Por lo que toca a la doctrina, la respuesta, parcialmente, parece depender de qué naturaleza jurídica se asigne a la acción redhibitoria. Por otra parte, una mirada a las decisiones de los tribunales muestra que, a veces, parecen aplicar el principio de especialidad; en otras ni siquiera consideran el concurso y, finalmente, en otras ocasiones, teniéndolo en cuenta, lo resuelven dando opción al comprador, aunque sin justificar por qué.

b) Entre la acción de daños del artículo 1861 y aquella de carácter general. Tratándose de este concurso la pregunta con que hemos de comenzar es, en apariencia, paradójica: ¿̇tiene sentido preguntarse acerca de la forma en que debe resolverse el concurso? La pregunta tiene, sin embargo, sentido porque la importancia de decidir cómo se resuelve un conflicto se relaciona, principalmente, con el hecho de que las acciones que entran en concurso tengan un tratamiento diverso.

$¿$ Tienen estas acciones un tratamiento diverso? Para considerar esta pregunta, deberemos considerar al plazo de prescripción de la acción de daños del artículo 1861 y la general de daños.

Para entender la cuestión de la prescripción de las acciones, haremos bien en recordar la sentencia de 31 de octubre de 2012 y la defensa de la demandada que consistió en señalar que la acción de daños se encontraba prescrita. Se trataba de la acción de daños regulada en el artículo 1861 y lo que la demandada asumía es que el plazo de prescripción de esa acción era diverso del plazo de prescripción de la acción general de daños.

Pues bien, si esto es correcto, entonces tiene sentido pronunciarse al respecto acerca de la forma en que ha de solucionarse el concurso únicamente en la medida en que asumamos que los plazos de prescripción son distintos. De otra forma, la cuestión carece de interés práctico.

Tanto la doctrina nacional como los tribunales han discutido el punto, preguntándose si la acción del artículo 1.861 es autónoma o dependiente de la acción redhibitoria y quanti minoris ${ }^{11}$.

Por lo que refiere a la doctrina, según la autorizada opinión de Alessandri Rodríguez la acción indemnizatoria sería dependiente de las acciones edilicias y, por lo tanto, su plazo de prescripción es el mismo ${ }^{52}$. No obstante la impor-

lo que procedía era la acción redhibitoria, sin embargo, sin mayor reflexión, el tribunal declaró resuelto el contrato.

${ }^{51} \mathrm{Al}$ respecto puede consultarse GuZmán, A., cit. (n. 27); pp. 115-118, CAPrile, B. (n. 35), pp. 586-587; y Oviedo AlbÁn, J., cit. (n. 11), pp. 329-351.

${ }^{52}$ Alessandri Rodríguez, A., De la compraventa, cit. (n. 10), II,1, pp. 258259. 
tancia de este autor en temas de compraventa, probablemente haremos bien en no seguirlo en este punto. En particular, porque con mayores antecedentes históricos y una argumentación jurídica más persuasiva Alejandro Guzmán ha demostrado que los plazos de prescripción son diversos ${ }^{53}$. En igual sentido se ha pronunciado Jorge Oviedo ${ }^{54}$ quien, además, añade que, tratándose de los tribunales, si bien ha existido ambigüedad, parece ser que, últimamente, han tendido a uniformarse considerando que la acción indemnizatoria tiene carácter autónomo 55 .

Se trataría, entonces, de una acción autónoma cuyo plazo de prescripción correspondería al plazo general de 5 años, es decir: el mismo de la acción general de daños. Bajo esas condiciones, la solución al concurso carece de interés práctico. Para entenderlo, bastará recordar por qué, en la sentencia de 31 de octubre de 2012, la demandada se defendió alegando que se trataba de la acción indemnizatoria del 1861 y la razón es que estimó que se trataba de una acción accesoria a las edilicias, por lo mismo, su prescripción era igual a la de aquellas. En la medida en que se asuma que el plazo de prescripción corresponde exactamente al de la acción resolutoria del artículo 1489 la defensa pierde todo interés.

Como se ve, entonces, la forma de resolver este concurso pasa por determinar el plazo de prescripción de la acción del artículo 1.861 y, a este respecto, se ha presentado la duda, tanto respecto de la doctrina como de los tribunales, sobre si se trata del plazo de prescripción general o aquel de las acciones propias de las acciones edilicias.

\section{Concursos verticales.}

a) Acción resolutoria y error. Podemos comenzar recordando este texto de Alessandri Besa: "El error sobre una cualidad accidental de la cosa, que una de las partes ha elevado a la categoría de motivo determinante del contrato, no debe confundirse con la situación que se presenta cuando una de ellas pone como condición que la cosa sobre la que versa el contrato tenga una calidad determinante, y la otra acepta el contrato en estos términos. En este segundo caso, la existencia de esa calidad en la cosa objeto del contrato es una de las estipulaciones del mismo, de modo que si la cosa no la contiene, no hay error sustancial, sino que incumplimiento del contrato por una de las partes. El efecto es, entonces, la resolución del contrato, o su cumplimiento

${ }^{53}$ GuZmán, A., cit. (n. 27), pp. 116-119, con base en dos argumentos: la ausencia de un título para enriquecer al vendedor y las diferencias que existe entre las acciones redhibitorias y de los artículos 1867 y 1868 con respecto a la del artículo 1861 .

${ }^{54}$ Oviedo Albán, J., cit. (n. 6) p. 351.

${ }^{55}$ Ibíd., P. 346. 
forzado, con indemnización de perjuicios (siempre que se trate de un contrato bilateral), en vez de la rescisión del mismo" 56 .

He dedicado otro trabajo a mostrar que esta idea es incorrecta ${ }^{57}$. De manera que aquí bastará proceder sumariamente. Ante todo, los tribunales nacionales parecen aceptar que, frente a un concurso entre error y resolución, el acreedor pueda optar por incardinar su pretensión en cualquiera de las dos figuras. Así, por ejemplo, sucede, como se recordará, en el caso resuelto por la sentencia de 27 de julio de 2005 . Igualmente lo han considerado los tribunales tratándose del contrato de arrendamiento ${ }^{58}$.

Por otra parte, convendrá advertir que, a diferencia, del concurso entre resolución y vicios redhibitorios, en el caso que ahora nos ocupa (resoluciónerror) no se presenta la relación especialidad-generalidad que permitía considerar que la disciplina de los vicios redhibitorios desplaza al régimen general de la resolución. En el Código Civil el error no es especial ni general respecto de la resolución, sino que operan en niveles distintos. El error se desenvuelve en el campo de la validez, en tanto la resolución opera en el campo del incumplimiento.

De esta manera, todo indica que el concurso se resuelve por acumulación alternativa. Es decir, el comprador puede elegir entre incardinar su pretensión en la disciplina de la resolución o en aquella del error vicio del consentimiento.

b) Vicios redhibitorios y error. Una vez más hemos de considerar si la calificación de los vicios redhibitorios corresponde a un supuesto especial de acción resolutoria por incumplimiento de la obligación de entrega o bien a un supuesto especial de error.

La razón es evidente, cómo ha sugerido Verda y Beamonte, si consideramos que se trata de un supuesto especial de error - una concreta aplicación de la doctrina del error en sede de compraventa- tendremos que entender que las normas de los vicios redhibitorios desplazan a las reglas generales del error: "por una elemental aplicación de la regla según la cual 'lex specialis derogat legi generali"'59.

Desde luego, si, en cambio, consideramos que se trata de una manifestación concreta de la acción resolutoria la relación general-especial no llega a producirse.

${ }^{56}$ Alessandri Besa, A., cit. n. (n. 31), p. 33.

${ }^{57}$ De la MaZA, I., cit. (n. 8).

${ }^{58}$ Sobre esto - para una mirada a los casos de arrendamiento- puede consultarse DE LA Maza, I., cit. (n. 8), pp. 222-223.

${ }^{59}$ Verda y Beamonte, J. R., cit. (n. 18), pp. 238-239. En el mismo sentido CaPRILE, B., cit. (n. 35), pp. 579. 
En la doctrina nacional se han ocupado de la cuestión Caprile ${ }^{60}$ y Oviedo $^{61}$. El primero comienza advirtiendo un par de casos de los tribunales en que se distingue entre las acciones redhibitoria y de nulidad. Sin embargo, la distinción obedece a que los defectos alegados no eran intrínsecos de la cosa, por lo mismo, en rigor, no hay concurso. Señala, a continuación la forma en que se ha resuelto en Francia y España. Advirtiendo que, en este último país, ha sido frecuente: $i$ ) considerarlo una especie de error; y ii) aceptar la invocación de la nulidad por error según las reglas generales.

Por su parte, Oviedo examina la disciplina del error, sus requisitos y consecuencias, señalando una cierta tendencia a la asimilación entre error con trascendencia anulatoria y vicios redhibitorios en el derecho chileno y colombiano. Al examinar la posición de los tribunales superiores de justicia en estos dos países, establece que han resuelto casos sirviéndose de la disciplina de los vicios redhibitorios que, perfectamente, podrían haber resuelto acudiendo a la disciplina del error vicio del consentimiento. Más adelante, Oviedo parece estimar que conceder la opción entre las reglas generales del error y aquellas propias de los vicios del consentimiento "se encuentra con el tropiezo de la aplicación de la regla de lógica jurídica según la cual la ley especial prevalece sobre la general"62.

Pues bien, de todo lo dicho en este último apartado parece desprenderse que la resolución de este concurso pasa-como sucedía en el concurso con las normas generales de la resolución- por determinar la naturaleza jurídica de la acción redhibitoria y, una vez más, no tenemos claridad respecto de ella.

\section{Sintesis.}

Esta parte de nuestro trabajo ha pretendido mostrar que la forma en que han de resolverse los concursos. Lo que descubrimos es que la solución no suele ser pacífica. Es frecuente que nos tropecemos con problemas relativos a la calificación jurídica de las figuras y que esos problemas no se encuentren solucionados, por lo mismo, tampoco podemos solucionar pacíficamente el problema del concurso.

La conclusión general que podemos obtener de esta tercera parte es que el sistema de tutela del comprador frente a la ausencia de cualidades presupuestas en la cosa resulta extremada $-y$, según veremos en la siguiente parte- e innecesariamente enrevesado. Y, convendrá advertirlo, por razones de espacio, he prescindido de otras posibles situaciones de concurso, así, por ejemplo, aquella entre el dolo in contrabendo y la resolución o las acciones

\footnotetext{
${ }^{60}$ CAPrile, B., cit. (n. 35), pp. 574-578.

${ }^{61}$ Oviedo (n. 11) pp. 141-207.

${ }^{62}$ Ibíd., p. 303.
} 
del artículo 1814 en relación al error, los vicios redhibitorios y la resolución, que, probablemente, complejicen aún más las cosas.

Como sea que fuere, creo que el punto está hecho: el sistema de tutela es extremadamente complejo, los perfiles de los medios de tutela se sobreponen entre si y generan situaciones de incertidumbre ${ }^{63}$.

\section{HaCia Un SISTEMA MÁS ADECUAdo DE PROTECCIÓN DEL COMPRADOR}

\section{Un derecho del incumplimiento contractual innecesariamente complejo.}

Comencemos recordando algunas palabras de Pantaleón Prieto: "La primera premisa de un Derecho del incumplimiento contractual congruente valorativamente y altamente eficiente es la previsión de una disciplina sustancialmente unitaria para toda desviación del programa contractual: de un conjunto de remedios o medios de tu tela del acreedor sustancialmente común para los casos de imposibilidad de la prestación, sobrevenida u originaria, mora y cumplimiento defectuoso, incluyéndose en este la evicción y las cargas o los vicios ocultos de la cosca vendida, los defectos de calidad o de cabida del inmueble vendido, y los llamados 'vicios ruinógenos' en el contrato de obra. Ello requerirá modificaciones de bastante entidad en nuestro Código Civil" ${ }^{64}$.

Si Pantaleón lleva razón, tendremos que concluir que nuestro derecho del incumplimiento contractual no es ni valorativamente congruente ni altamente eficiente.

$Y$ es que como ha sido enfatizado muchas veces ${ }^{65}-y$ espero que este trabajo vuelva a hacerlo- en el ámbito chileno carecemos de "una disciplina unitaria para toda desviación del programa contractual”. Tratándose de la compraventa convive el régimen general del incumplimiento con otros sistemas especiales como la cabida, la evicción y los vicios redhibitorios.

Se trata, además, de un sistema que mezcla obligaciones con garantías. Así, por ejemplo Carrasco Perera, ha señalado, respecto del derecho español la siguiente idea que, mutatis mutandis, resulta perfectamente aplicable a

${ }^{63}$ En este sentido Morales Moreno, A. M., cit. (n. 9), p. 38, refiriéndose a la convivencia entre el régimen de los vicios redhibitorios y la resolución ha señalado: "En la práctica opera un doble régimen, lo cual es fuente de inseguridad jurídica”.

${ }^{64}$ Pantaleón Prieto, Fernando, Las nuevas bases de la responsabilidad contractual, en Anuario de Derecho Civil, 46(1993) 4, pp. 1720-1721.

${ }^{65}$ Véase, por ejemplo, De la Maza, I., cit. (n. 3); Vidal Olivares, Álvaro, El incumplimiento de obligaciones con objeto fungible y los remedios del acreedor afectado, en Pizarro, Carlos - VIDAL, Álvaro, Incumplimiento contractual, resolución e indemnización de daños (Bogotá, Editorial Universidad del Rosario, 2010). 
nuestra situación: "Para el CC la obligación por excelencia es la de entrega de la cosa, y la anomalía básica en el cumplimiento, después de la mora, es la falta de conformidad, el defecto de la cosa. Con todo, la legislación no es congruente en sus principios. Así, la venta de cosa es pecífica con defectos ocultos no es considerada en los artículos 1474, 1484 y 1486 CC. como una forma de incumplimiento contractual por 'contravención', sino como una suerte de deber de garantía (saneamiento). No es que el vendedor res ponda por la existencia de defectos ocultos, sino que la aparición de un defecto de esta clase hace nacer en cabeza del vendedor una nueva obligación, de devolver la cosa o reducir el precio"66.

En fin, a lo anterior, todavía podemos añadir que no contamos con un sistema de medios de tutela debidamente articulado y que carecemos de normas que solucionen los concursos verticales.

El punto es que este diseño del Código Civil no obedece necesidades dogmáticas o de lógica jurídica, sino, nada más, a razones históricas ${ }^{67}$. Ninguna de esas razones resulta hoy día persuasiva para mantener el sistema fragmentario de tutela del comprador que, como se ha visto, resulta extremada e innecesariamente complejo, por lo mismo, debe superarse ${ }^{68}$. El número siguiente indica algunas líneas generales para pensar en esa superación, para pensar en reglas simples para un mundo complejo.

\section{Reglas simples para un mundo complejo ${ }^{69}$.}

La pregunta que hemos de hacernos es cómo diseñar un sistema de tutela del comprador que aligere la complejidad del actual. $Y$ en esta tarea, afortunadamente, contamos con abundante material del cual servirnos.

Para ver cómo servirnos de este material haremos bien en recordar que el problema que presenta el actual diseño de tutela del comprador frente a la ausencia de cualidades presupuestas de la cosa se relaciona, de una parte, con un concepto de incumplimiento fragmentario que distingue entre la entrega y el saneamiento; y, por otra parte, con la inevitable superposición

${ }^{66}$ Carrasco Perera, Ángel, Derecho de contratos (Cizur Menor [Navarra], Thomson Reuters, 2010), pp. 889-890.

${ }^{67}$ Véase ZimmermanN, Reinhard, El nuevo derecho alemán de las obligaciones (trad. de De Arroyo i Amayuelas, Esther, Barcelona, Bosch, 2008), pp. 91-99.

${ }^{68}$ Véase: Morales Moreno, Antonio Manuel, Adaptación del Código Civil al Derecho europeo: la compraventa, en Morales Moreno, Antonio Manuel, La modernización del derecho de obligaciones (Cizur Menor [Navarra], Thomson - Civitas, 2006), pp. 98-101.

${ }^{69}$ Como es evidente, tomo este título de Epstein, Richard, Simple Rules for a Complex World (Massachussets, Harvard University Press, 1995). 
que se produce entre medios de tutela generales y especiales y entre estos y acciones de nulidad.

Por lo tanto, la respuesta frente a la pregunta acerca de un diseño más sencillo del sistema de tutela del comprador supone por $i$ ) una noción de incumplimiento amplia y unitaria; ii) un sistema ordenado de mecanismo de tutela del comprador; y $i i i$ ) unas reglas que nos permitan decidir los concursos entre acciones de incumplimiento y acciones de nulidad.

Estas cuestiones han sido consideradas ya en el derecho uniforme ${ }^{70} \mathrm{y}$ en ciertos instrumentos de "soft law"71, por lo mismo, haremos bien en tenerlos presentes.

\section{La noción de incumplimiento.}

Como se ha visto, en el tratamiento que prodiga el Código Civil a la compraventa el incumplimiento es fragmentario, distinguiendo la obligación de entrega de la de saneamiento. Podemos añadir ahora, recordando la sentencia de 31 de octubre de 2012 que, además, se trata de una noción de incumplimiento restringida que no incorpora los casos de inexistencia física parcial o total de la cosa vendida a que refiere el artículo 1814. Esta situación, ya se ha señalado, origina los concursos de acciones y los problemas que ellos aparejan.

Si lo anterior es correcto, entonces una forma de diluir los concursos -y sus problemas- consisten en disponer de una noción de incumplimiento unitaria y amplia. La doctrina se ha preocupado ampliamente de este tema, de manera que podemos servirnos de la opinión especialmente autorizada de Antonio Manuel Morales Moreno para señalar cómo deben ser los perfiles de esa noción de incumplimiento. Señala este autor: "En cuando a la amplitud, abarca cualquier manifestación de la falta de realización de las exigencias del contrato, garantizadas por el deudor. Se refiere, utilizando la distinción que he hecho más arriba, tanto a la inejecución de la conducta debida como al hecho de que las circunstancias fácticas, presupuestas y garantizadas por el contrato no se den en la realidad (lo que se explica por un error), como a la falta de consecución del resultado garantizado por el deudor al acreedor. Esa amplitud permite integrar en el sistema general del incumplimiento los sistemas especiales de responsabilidad contractual, previstos en los códigos del (CISG).

${ }^{70} \mathrm{Me}$ refiero aquí a Convención sobre compraventa internacional de mercaderías

${ }^{71}$ Pienso aquí especialmente en los Principios Europeos de Derecho de Contratos (PECL), los Principios UNIDROIT sobre contratos comerciales internacionales (PCCI.), el Principles, Definitions and Model Rules of European Private Law Draft Common Frame of Reference (DCFR.) y en el Proposal for a Regulation of the European Parliament and of the Council Common European Sales Law (CESL.). 
siglo XIX, los denominados saneamientos. Así, en la venta de un inmueble, es incumplimiento que el vendedor no entregue al comprador una parte del terreno, o que el terreno no tenga toda la extensión asignada al mismo (presupuesta en él), si el vendedor garantiza esa extensión (cfr. artículos 1469 a 1471 CC.); también es incumplimiento el que el comprador no llegue a adquirir la propiedad de la cosa vendida, por pertenecer está a un tercero (arts. 1475 a 1482 CC); o que la cosa esté gravada con cargas o servidumbres que el comprador no tiene que soportar, conforme al contrato (artículo 1483 CC.); o que sea defectuosa (artículos 1484 a 1499 CC.) o, en general, no sea cualitativamente conforme a las exigencias del contrato (artículos 35, 36 CISG.)./ En el nuevo sistema de responsabilidad contractual hay incumplimiento en casos de imposibilidad inicial no imputable al deudor, si queda insatisfecho el interés del acreedor. Las posibles diferencias entre el incumplimiento voluntario y el fortuito no se encuentran consideradas en el supuesto general del incumplimiento; pueden aparecer en el supuesto especial de aplicación de alguno de los remedios (así, por ejemplo, en el remedio de la indemnización)./ Por fin, también es indiferente para determinar si existe o no incumplimiento, el que el mismo consista en la total inejecución de la prestación, en un retraso, o consista en un cumplimiento defectuoso, en cualquiera de sus manifestaciones" 72 .

Se trata entonces de una noción de incumplimiento unitaria y amplia, frecuente en el derecho uniforme $e^{73}$ y en los textos de "soft law" ya sea sobre contratos en general ${ }^{74} \mathrm{o}$, específicamente sobre el contrato de compraventa ${ }^{75}$.

La noción es unitaria porque integra en un solo concepto el sistema de tutela general del comprador y aquellos especiales como los vicios redhibitorios, los defectos de cabida y la evicción. Por otra parte, es amplia porque considera como incumplimiento contractual los casos de imputabilidad inicial no imputables al vendedor.

Pues bien, ahora podemos preguntarnos en qué sentido una noción de incumplimiento como ésta contribuye a disminuir la complejidad de la operativa de la tutela del comprador frente a la entrega de una cosa sin las cualidades presupuestas. Y la respuesta debería resultar más o menos evidente. Con una noción de incumplimiento contractual amplia y unitaria lo único

${ }^{72}$ Morales Moreno, Antonio Manuel, Claves de la modernización del derecho de contratos, en Autonomía de la voluntad en el derecho privado. Estudios en conmemoración del 150 aniversario de la ley del Notariado (Madrid, Consejo General del Notariado, 2013), III,1, pp. 391-392.

${ }^{73}$ Véanse, por ejemplo, los artículos 45 y 61 CISG.

${ }^{74}$ Véanse, por ejemplo, los artículos 1,301 (4) PECL, 7,1,1 PCCI y III, 1,101(3) DCFR.

${ }^{75}$ Véase el artículo 87 CESL. 
que debemos preguntarnos es si esa cualidad se había incorporado al contrato en términos de que éste proteja al comprador frente a su ausencia. Si la respuesta es positiva ya no es necesario pensar cómo ha de incardinarse, si como un vicio redhibitorio, como un problema de cabida, como un problema de imposibilidad inicial o un supuesto de acción resolutoria. Simplemente se trata de un supuesto de incumplimiento contractual. Al operar de esta manera la noción amplia y unitaria de incumplimiento suprime el problema de los concursos horizontales porque, en definitiva, suprime los sistemas especiales de tutela del comprador e incorpora la imposibilidad inicial como un supuesto de incumplimiento.

\section{Un sistema articulado de medios de tutela del acreedor.}

$\mathrm{Si}$ cualquier desviación del programa contractual constituye incumplimiento, verificada esa desviación la pregunta que resta es qué mecanismo de tutela procede. Lo primero que tendremos que advertir aquí es que como ha sido señalado por la doctrina nacional el Código Civil carece de un sistema articulado de medios de tutela del acreedor, en este caso del comprador. En este sentido, por ejemplo, el profesor Carlos Pizarro ha sostenido que: "[...] no existe en el Código un sistema sobre los efectos del incumplimiento, sólo disposiciones dispersas, generales y especiales, cuya estricta y aislada aplicación no ofrece una eficiente protección del interés del acreedor afectado por el incumplimiento"76.

Para constatar la corrección de la afirmación de Pizarro basta una somera comparación entre el diseño del Código Civil al respecto y, por ejemplo, el diseño de los PECL., de los PCCI. o del CESL.

Sin ánimo de exhaustividad, tratándose del Código Civil podemos advertir que la principal regla respecto de las consecuencias del incumplimiento de obligaciones de dar se encuentra a propósito de la clasificación de las obligaciones, específicamente a propósito de las condicionales en el artículo $1489^{77}$ y la suspensión del cumplimiento parece estar tratada a propósito de la constitución de la mora ${ }^{78}$. Por otra parte, el problema no es sólo de

${ }^{76}$ PiZARro, Carlos - VIDAL, Álvaro, Incumplimiento contractual, resolución e indemnización de daños Bogotá, Editorial Universidad del Rosario, 2010), pp. 213-214.

${ }^{77}$ Sobre la explicación histórica de esta ubicación, más bien incomprensible, puede consultarse San miguel Pradera, Lis, La modernización del Derecho de Obligaciones y la resolución por incumplimiento en los ordenamientos español y chileno, en Iñigo DE LA MAZA (editor) Incumplimiento contractual: nuevas perspectivas (Cuadernos de Análisis Jurídicos, Colección de Derecho Privado VII, Santiago, Universidad Diego Portales, 2011), pp. 111-114.

${ }^{78} \mathrm{Si}$ es que es realmente ese medio de tutela lo que allí se trata. Al respecto puede consultarse: Mejías Alonzo, Claudia, La excepción de contrato no cumplido y su consagración en el código civil chileno, en Revista Chilena de Derecho, 40 (2013) 2. 
ubicación, también se refiere al supuesto de hecho que activa cada uno de los medios de tutela. Únicamente considerando los dos ya señalados, resulta difícil exagerar las dificultades de aplicación que ha generado la parquedad del Código al respecto ${ }^{79}$. Si consideramos ahora los PECL., advertiremos que su capítulo 8 se encuentra destinado a organizar la convivencia de los remedios disponibles para el acreedor en caso de incumplimiento y su capítulo 9 detalla el supuesto de hecho de cada uno de esos remedios. Por su parte, tratándose de los PCCI., sucede algo similar tratándose de su extenso capítulo $7^{\circ}$. En fin, la misma situación se reproduce en el capítulo 10 CESL.

Desde luego no es el objeto de este trabajo ofrecer un recuento detallado acerca de cómo debiese organizarse ese sistema de tutela. La pretensión es mucho más modesta, se trata de ofrecer a la luz de lo dicho por la doctrina y algunos materiales propios del derecho comprado tres guías generales al respecto.

La primera de ellas corresponde a la articulación de los medios de tutela con el incumplimiento y es que, por así decirlo, el incumplimiento contractual -entendido en el sentido unitario y amplio que ha sido señalado- es, por así decirlo, la puerta de entrada a los medios de tutela del comprador ${ }^{80}$.

La segunda guía corresponde al supuesto de hecho de cada medio de tutela. A diferencia de lo que sucede en el Código Civil chileno lo deseable es que el supuesto de hecho o las condiciones de aplicación se encuentren suficientemente especificadas en la regulación ${ }^{81}$. Así, por ejemplo, respecto

${ }^{79}$ Respecto de la resolución puede consultarse PeÑailillo Arévalo, Daniel, $\mathrm{Al}$ gunas reformas a la resolución por incumplimiento, en Revista de Derecho Universidad de Concepción, 231-232 (2012). Sobre las dificultades que ha planteado la excepción de contrapto no cumplido puede consultarse Caprile Biermann, Bruno, Algunos problemas ofrecidos por la excepción de contrato no cumplido y, en especial, el de su invocación para atajar la acción resolutoria en el caso de incumplimiento recíproco de los contratantes, en Revista de Derecho de la Pontificia Universidad Católica de Valparaiso, 39 (Valparaíso, 2012) 2.

${ }^{80}$ Una excepción a esto, sin embargo, se encuentra en la resolución por incumplimiento previsible. Sobre el tema, en el ámbito nacional, puede consultarse CoNTARDo GoNZÁLEZ, Juan, La resolución por anticipación o por incumplimiento previsible. Intento de construcción a partir de los artículos 1826 del Código Civily 147 del Código de Comercio, en Carmen Domínguez y otros (coordinadores), Estudios de Derecho Civil (Santiago, LegalPublishing), VIII.

${ }^{81}$ Como señala Morales Moreno, A. M., cit. (n. 72), p. 399: un sistema de remedios implica la existencia de una pluralidad de remedios. Cada remedio tiene (o puede tener) un supuesto especial, complementario del general, que en nuestro caso es el incumplimiento. El supuesto especial de cada remedio dosifica su aplicación. Así, por ejemplo, en el sistema de remedios del incumplimiento la reducción del precio, por su propia naturaleza, solo exige una modalidad de incumplimiento, consistente en la falta de conformidad de la prestación, pero nada más; la resolución, en cambio, tiene requi- 
de la resolución, el hecho de que requiere de un incumplimiento esencial y que no es necesario que provenga de la culpa o dolo del deudor; o respecto de la acción de daños que puede interponerse sin necesidad de acoplarla a una pretensión de cumplimiento forzado o resolutoria; o, en fin, respecto del cumplimiento forzoso, cómo queda limitado por la operación de reemplazo ${ }^{82}$.

La tercera guía se refiere a qué remedios deberían estar disponibles para el comprador. Desde luego hemos de considerar el cumplimiento forzoso, la resolución y la indemnización de perjuicios. Sin embargo, la adecuada protección del comprador exige añadir la reducción del precio ${ }^{83}$ - hoy día confinada a regímenes especiales de tutela- y extender la pretensión de cumplimiento a la reparación o sustitución de la cosa cuando ello resulte posible ${ }^{84}$.

\section{Concursos verticales.}

Los dos apartados anteriores se han referido a los concursos horizontales. Sin embargo, como se ha visto, también es posible la presencia de concursos verticales. Por lo tanto, es necesario hacerse cargo de ellos. Y las posibilidades son dos.

A la primera de ellas se refiere el artículo 3,7 PCCI., que dispone lo siguiente: "Una parte no puede anular el contrato a causa de error si los hechos en los que basa su pretensión le otorgan o le podrian haber otorgado remedios por incumplimiento".

La segunda posibilidad está considerada en el artículo 4,119 PECL., según el cual: "La parte que tenga derecho a utilizar alguno de los remedios que le concede el presente capitulo y que se encuentre al mismo tiempo en circunstancias quelepermiten utilizar un remedio fundado en el incumplimiento, puede optar por cualquiera de ellos".

¿Cuál de las dos posibilidades debe elegirse? Para considerar la respuesta a esta pregunta haremos bien en advertir por qué ambos instrumentos optan por soluciones distintas. Tratándose de los PCCI., deberemos poner atención a los Comentarios de dicho precepto y allí encontramos que los remedios del incumplimiento "ofrece[n] una mejor solución y resulta[n] más flexible[s] que la solución tajante de la nulidad".

Apoyando esta solución Fenoy Picon considera razonable la preferencia

sitos complementarios del incumplimiento (por ej.: incumplimiento esencial, ofrecer un plazo para el cumplimiento); la indemnización de daños puede exigir la culpa del deudor, o bien, funcionar de modo objetivo.

${ }^{82}$ Sobre esto puede consultarse Morales Moreno, A. M., cit. (n. 72), pp. 404410.

${ }^{83}$ Sobre el tema puede consultarse Ferrante, Alfredo, La reducción del precio en la compraventa (Cizur Menor [Navarra], Thomson Reuters, 2012).

${ }^{84}$ Ver Morales Moreno, A. M., cit. (n. 72), pp. 401-403. 
de la disciplina del incumplimiento ${ }^{85}$. Opina esta autora que, de una parte, el concepto de incumplimiento sobre el cual se estructuran los PCCI. incorporan las cualidades de la cosa al deber de prestación, con independencia del hecho de que se trate de una obligación de género o de especie o cuerpo cierto ${ }^{86}$. Por otra parte, continúa, es preferible la disciplina del incumplimiento toda vez que: "[...] el elenco de los remedios por incumplimiento (cumplimiento, resolución, indemnización) de los Principios de UnIDRoIT es más amplio y de distinto alcance que los del error (anulación, indemnización), da una más adecuada protección al acreedor lesionado" 87 .

Tratándose de los PECL., al igual que en los PCCI., la justificación que es posible encontrar respecto de la acumulación alternativa no resulta particularmente articulada. En el Comentario del artículo 4,119 se lee: "In some situations the same facts may be analysed either as a case of mistake or incorrect information, or as one in which there is a non-performance. For example there may be a remedy for non-performance under Article 6:108 Quality of Performance, because the performance of the one party is not of average quality; or one party may have given a contractual undertaking that a particular fact relating to the performance is true...Statements giving rise to Contractual Obligations./ In such cases there seems no good reasons to prevent the aggrieved party from choosing which set of remedies to pursue. Normally the remedies for non-performance will give a fuller measure of recovery, but the aggrieved party may find simpler to exercise its rights under this Chapter, e.g. just to give notice of avoidance on the ground of mistake".

En conformidad a los párrafos citados la razón para conceder al titular de la acción una acumulación alternativa de acciones sería que no existe una buena razón para no hacerlo.

Pues bien, siguiendo la opinión de Fenoy Picon, parece preferible la solución de los PCCI. pues la autora lleva razón cuando advierte que el régimen del incumplimiento resulta más dúctil que el de la nulidad y permite equilibrar más satisfactoriamente la tutela de los intereses del acreedor y el deudor.

\section{A MANERA DE CONCLUSIÓN: LA PESADILLA Y EL SUEÑO NOBLE}

En una famosa conferencia que dictó en la Universidad de Georgia el 14

\footnotetext{
${ }^{85}$ Fenoy Picon, Nieves, La modernización del régimen del incumplimiento del contrato: Propuestas de la Comisión General de Codificación. Parte primera: Aspectos generales. El incumplimiento, en Anuario de Derecho Civil, 63 (2010) 1, pp. 203-207.

${ }^{86}$ Ibíd., p 202.

${ }^{87}$ Ibíd., pp. 204-205.
} 
de abril de 1977, Herbert Hart ${ }^{88}$ se refirió a dos extremos en la comprensión de la naturaleza del Derecho: la pesadilla y el noble sueño. La pesadilla correspondía a las visiones más extremas del realismo jurídico según las cuales Derecho era lo que los jueces decían que era Derecho. El sueño noble, en cambio, consistía en la creencia de que los jueces aplican el Derecho existente.

Lo que he querido mostrar en este trabajo es que nuestra pesadilla es un sistema de tutela del comprador frente a la ausencia de cualidades presupuestas de la cosa extremada e innecesariamente complejo que genera una amplia variedad de concursos cuya forma de resolverse no es clara y que, por lo mismo, complica una adecuada protección del comprador frente a este tipo de incumplimientos, por lo demás, tan frecuentes. El sueño noble corresponde a un sistema de tutela del comprador más sencillo y ordenado, en el cual existe una noción de incumplimiento unitaria y amplia, un sistema de medios de tutela correctamente articulados y normas que permitan resolver adecuadamente los concursos verticales.

Ahora bien, una mirada al derecho comparado y la opinión de la doctrina nos muestra que disponemos de abundante material para transitar desde la pesadilla al sueño noble.

\section{BiBLIOGRAFÍA}

Alessandri Besa, Arturo, La nulidady la rescisión en el derecho civil chileno (3a edición, Santiago, Editorial Jurídica de Chile, 2008), II.

Alessandri Rodríguez, Arturo, De la compraventa y de la promesa de venta (reimpresión Santiago, Editorial Jurídica de Chile, 2003), dos volúmenes

BARAONA González, Jorge, La acción redhibitoria como acción de nulidad, en Estudios de Derecho Civil (Santiago, LegalPublishing, 2008), III.

CAPRILE BIERMANN, Bruno, Las acciones del comprador insatisfecho: el cúmulo actual (ley de protección al consumidor, vicios redhibitorios, error sustancial, resolución por incumplimiento) y la tendencia al deber de conformidad en el derecho comparado. Mantilla Espinosa Fabricio - Pizarro Wilson, Carlos (coordinadores), Estudios de Derecho privado en homenaje a Christián Larroumet (Santiago, Editorial Fundación Fueyo - Universidad Diego Portales, 2008).

CAPRILE BIERMANn, Bruno, Algunos problemas ofrecidospor la excepción de contrato no cumplido y, en especial, el de su invocación para atajar la acción resolutoria en el caso de incumplimiento reciproco de los contratantes, en Revista de Derecho de la Pontificia Universidad Católica de Valparaíso, 39 (Valparaíso, 2012) 2.

Carrasco Perera, Ángel, Derecho de contratos (Cizur Menor [Navarra], Thomson Reuters, 2010).

${ }^{88}$ Hart, Herbert, American Jurisprudence Through English Eyes: The Nightmare and the Noble Dream, Sibley Lectures. Paper 33 (1977), en http://digitalcommons. law.uga.edu/lectures_pre_arch_lectures_sibley/33 
Contardo González, Juan, La resolución por anticipación o por incumplimiento previsible. Intento de construcción a partir de los artículos 1826 del Código Civily 147 del Código de Comercio, en Carmen Domínguez y otros (coordinadores), Estudios de Derecho Civil (Santiago, LegalPublishing), VIII.

De la Maza Gazmuri, Iñigo - Vidal olivares, Álvaro, Propósito práctico, incumplimiento contractual y remedios del acreedor: Con ocasión de tres recientes sentencias de la Corte Suprema, en Ius et Praxis, 20 (2014) 1.

DE LA MAZA GAZMURI, Iñigo, El concurso entre el error con trascendencia anulatoria y el incumplimiento resolutorio, en De la MAZA GAZMURI, Iñigo (editor), Incumplimiento contractual: nuevas perspectivas (Cuadernos de Análisis Jurídicos, Colección de Derecho Privado VII, Santiago, U. Diego Portales, 2011).

DE la Maza Gazmuri, Iñigo, El régimen de los cumplimientos defectuosos en la compraventa, en Revista Chilena de Derecho, 39 (2012) 3.

EPstein, Richard, Simple Rules for a Complex World (Massachussets, Harvard University Press, 1995).

Fenoy Picon, Nieves, Falta de conformidad e incumplimiento en la compraventa. Evolución del ordenamiento español (Madrid Colegio de Registradores de la Propiedad y Mercantiles de España Centro de Estudios Registrales, 1996).

Fenoy Picon, Nieves, La modernización del régimen del incumplimiento del contrato: Propuestas de la Comisión General de Codificación. Parte primera: Aspectos generales. El incumplimiento, en Anuario de Derecho Civil, 63 (2010) 1.

Ferrante, Alfredo, La reducción del precio en la compraventa (Cizur Menor [Navarra], Thomson Reuters, 2012).

Figueroa YÁÑEz, Gonzalo, Rescisión, resolución y redhibición: ¿puede hablarse de un cúmulo de acciones, en ZúÑIGa TEJos, A. (coordinador) Estudios de derecho privado, Libro homenaje al jurista René Abeliuk Manasevich (Santiago, Editorial Jurídica de Chile, 2011).

Goldie-Genicon, Charlotte, Contribution à l'étude des rapports entre le droit commun et le droit spécial des contrats (Paris, Librairie Général de Législation et Jurisprudence, 2009).

GuZMÁn BRITO, Alejandro, Sobre la relación entre las acciones de saneamiento de los vicios redhibitorios y las acciones comunes de indemnización, con especial referencia a su prescripción (Opinión profesional), en Revista Chilena de Derecho Privado, 9 (2007).

HaRT, Herbert (1977): American Jurisprudence Through English Eyes: The Nightmare and the Noble Dream, Sibley Lectures. Paper 33, en http://digitalcommons.law.uga. edu/lectures_pre_arch_lectures_sibley/33

López Díaz, Patricia, La indemnización compensatoria por incumplimiento de los contratos bilaterales como remedio autónomo en el derecho civil chileno, en Revista Chilena de Derecho Privado Fernando Fueyo Laneri, 15 (julio de 2010).

Mejías Alonzo, Claudia, El incumplimiento que faculta a resolver el contrato a la luz de las disposiciones del Código Civil, en DE LA MAZA, IÑIgo (coordinador), Incumplimiento contractual: nuevas perspectivas (Cuadernos de Análisis Jurídicos, Colección de Derecho Privado VII, Santiago, Universidad Diego Portales, 2011).

Mejías Alonzo, Claudia, La excepción de contrato no cumplido y su consagración en el código civil chileno, en Revista Chilena de Derecho, 40 (2013) 2.

Morales Moreno, Antonio Manuel, Evolución del concepto de obligación en derecho español, en El mismo, La modernización del derecho de obligaciones (Cizur Menor [Navarra], Thomson - Civitas, 2006). 
Morales Moreno, Antonio Manuel, Adaptación del Código Civil al Derecho europeo: la compraventa, en Morales Moreno, Antonio Manuel, La modernización del derecho de obligaciones, (Cizur Menor [Navarra], Thomson - Civitas, 2006).

Morales Moreno, Antonio Manuel, Claves de la modernización del derecho de contratos, en Autonomia de la voluntad en el derecho privado. Estudios en conmemoración del 150 aniversario de la ley del Notariado (Madrid, Consejo General del Notariado, 2013), III,1.

Morales Moreno, Antonio Manuel, El error en los contratos (Madrid, Ceura, 1988).

Morales Moreno, Antonio Manuel, Tres modelos de vinculación del vendedor en las cualidades de la cosa, en Anuario de Derecho Civil, 65 (2012) 1.

Oviedo Albán, Jorge, La garantía por vicios ocultos en la compraventa (Tesis doctoral, Santiago, Universidad de los Andes, 2012)

Oviedo Albán, Jorge, Sobre el concepto de vicio redhibitorio en la compraventa. Análisis comparado de la jurisprudencia chilena y colombiana, Revista Chilena de Derecho, $37(2010) 2$.

PANTAleón Prieto, Fernando, Las nuevas bases de la responsabilidad contractual, en Anuario de Derecho Civil, 46(1993) 4.

Peñailillo Arévalo, Daniel, Algunas reformas a la resolución por incumplimiento, en Revista de Derecho Universidad de Concepción, 231.-232 (2012).

Pizarro Wilson, Carlos, Hacia un sistema de remedios al incumplimiento contractual, en Pizarro, Carlos - Vidal, Álvaro, Incumplimiento contractual, resolución e indemnización de daños (Bogotá, Editorial Universidad del Rosario, 2010).

San miguel Pradera, Lis, La modernización del Derecho de Obligaciones y la resolución por incumplimiento en los ordenamientos español y chileno, en Iñigo DE LA MAZA (editor) Incumplimiento contractual: nuevas perspectivas (Cuadernos de Análisis Jurídicos, Colección de Derecho Privado VII, Santiago, Universiudad Diego Portales, 2011).

Verda y BeAmonte, José Ramón, Saneamiento poir vicios ocultos. Las acciones edilicias (Bogotá, Universidad del Rosario, 2009).

Vidal Olivares, Álvaro, El incumplimiento de obligaciones con objeto fungible y los remedios del acreedor afectado, en PIZARRo, Carlos - VIDAL, Álvaro, Incumplimiento contractual, resolución e indemnización de daños Bogotá, Editorial Universidad del Rosario, 2010).

Vidal Olivares, Álvaro, El incumplimiento resolutorio en el Código Civil. Condiciones deprocedencia de la resolución por incumplimiento, en PIZARRo Carlos (coordinador), Estudios de Derecho Civil (Santiago, LegalPublishing, 2009), IV.

Zimmermann, Reinhard, El nuevo derecho alemán de las obligaciones (trad. de De Arroyo i Amayuelas, Esther, Barcelona, Bosch, 2008). 
